
\title{
Improvement Programme
}

\section{ANNUAL REPORT 2018-19}
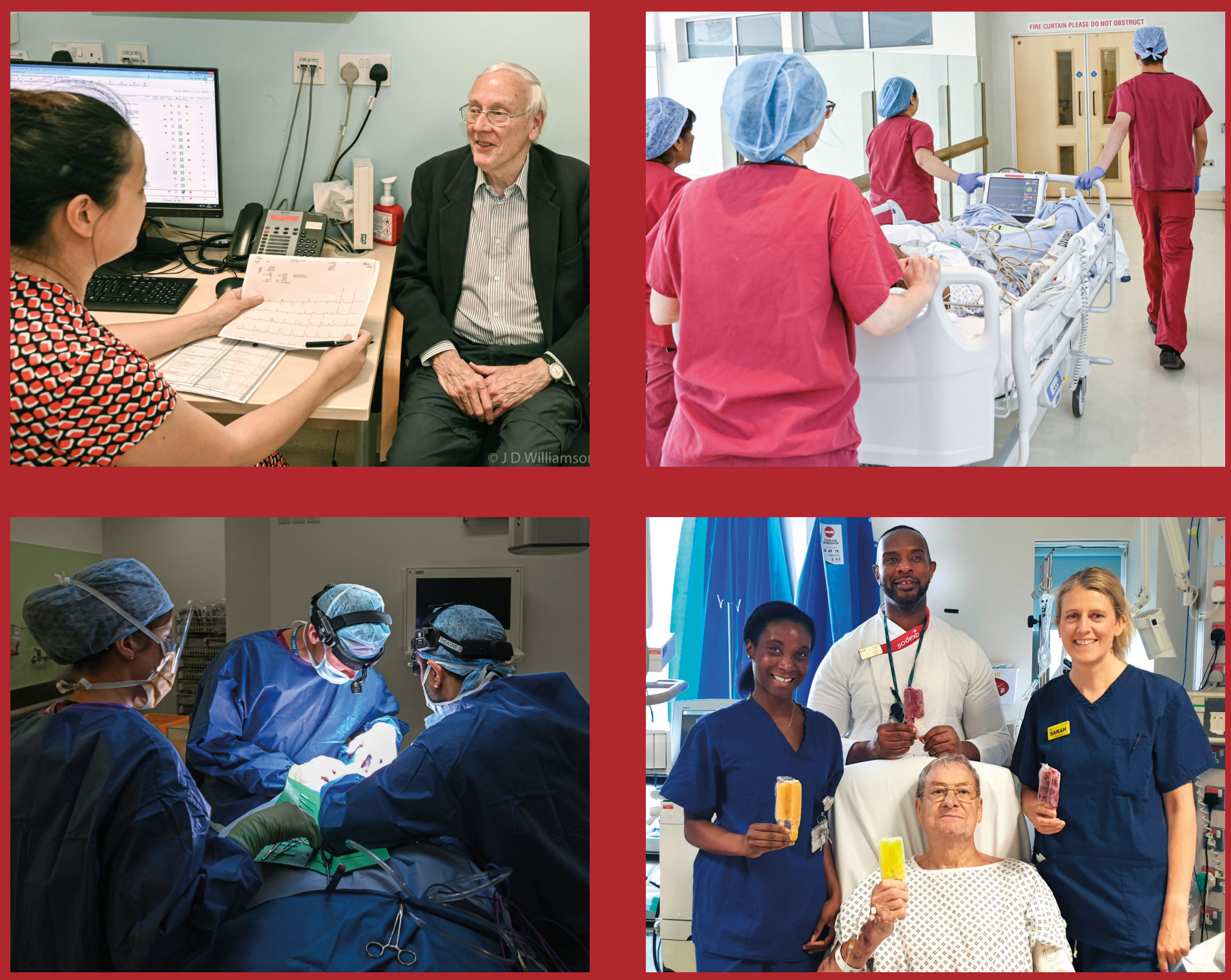

RCOA NIAASRRC Royal College of Anaesthetists
O

The

Health Foundation
AJal source 


\section{Contents}

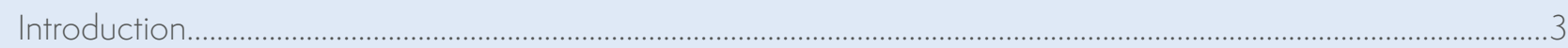

Top 5 National Improvement Opportunities for 2019-20 ...............................................................................

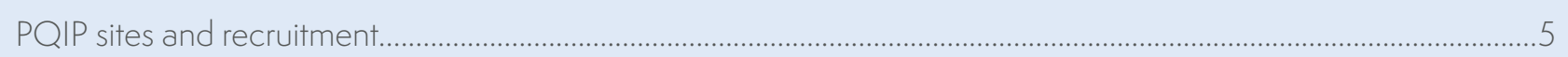

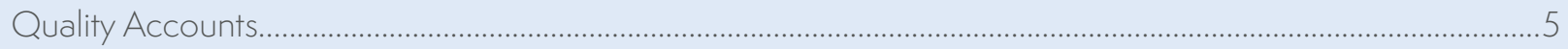

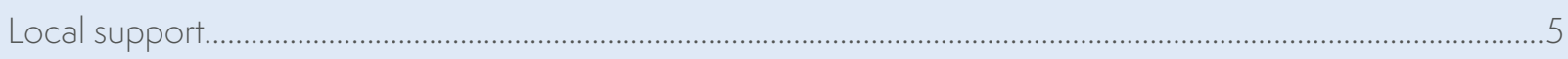

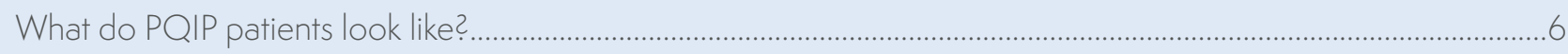

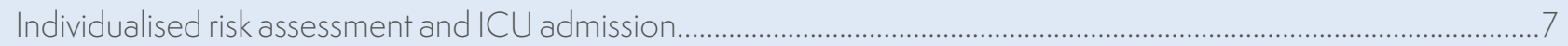

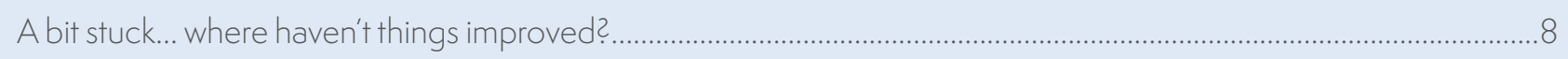

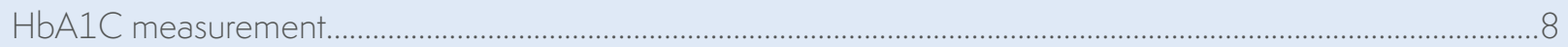

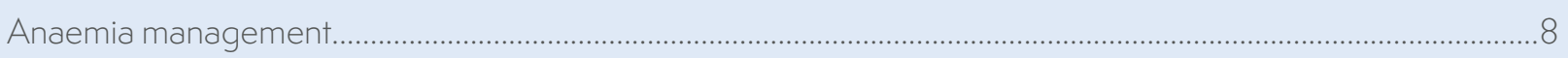

Sharing data and ideas to support local improvement.............................................................................................

Living the DrEaM

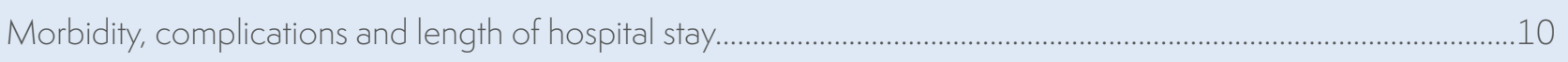

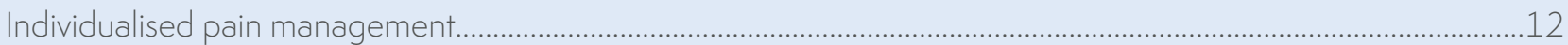

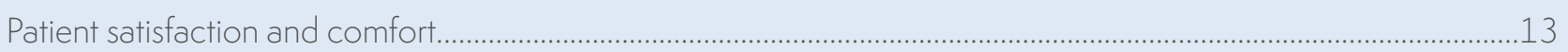

Using your data for local Ql projects.........................................................................................................

Longer-term patient reported outcomes.....................................................................................................................

Engaging staff, engaging patients, improving data collection and completion....................................................15

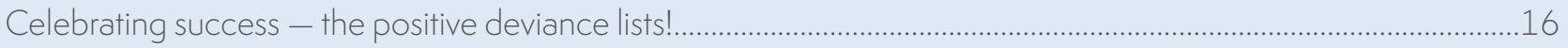

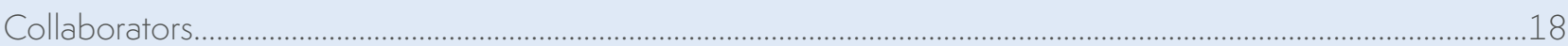

\section{Credits}

This report was prepared by the PQIP Project Team (see back cover for full list). It is dedicated to the memory of our friend and colleague David Gilhooly.

Design and layout by the Royal College of Anaesthetists.

\section{Cover photography}

Top left, top right and bottom left photos by JD Williamson (copyright). Bottom right photo by POM-POPS team, UCLH at Westmoreland Street. All photography used with consent. 


\title{
Welcome to the second PQIP Annual Report - steady as she goes
}

\section{Improving and growing}

The 2018-19 PQIP report tells a great story of national improvements in the care and outcome of surgical patients. We have been able to look at data from almost 20,000 people undergoing operations which can have a significant impact on health and quality of life. PQIP's aim is to reduce the risk of complications after major surgery through ensuring that patients get the best possible care throughout their perioperative pathway. The mechanism for delivering these improvements is to measure, report, and support local teams to act on their own quality data.

Even though we are still very early in our collective improvement endeavours, there have been some notable successes: most importantly, we have seen a drop in major postoperative morbidity and length of hospital stay. We have also seen an improvement in a suite of processes aimed at returning patients to normal function as soon as possible after surgery: Drinking, Eating and Mobilising (together known as DrEaMing). But there are still some tricky problems - anaemia management, individualised risk assessment, diabetes optimisation and acute pain management are all proving to be hard nuts to crack.

\section{Challenges and opportunities}

We know that making improvement happen takes time, effort and personnel - and all of these can be hard to come by for busy clinical teams working hard to deliver patient care. Alongside the main PQIP study, we are doing some additional research where social scientists are working with local teams to understand the challenges and opportunities for using PQIP data effectively. They have found that teams have huge enthusiasm for trying to make improvement happen, but can lack time, resources or a supportive culture for delivering QI projects. Giving attention to PQIP goals can be difficult when we all have so many competing priorities.

So, this year we are launching a series of competitions aimed at promoting some local Ql activity and spreading stories of good news and success. We are looking for improvement projects in the specific areas of diabetes detection and management, individualised risk assessment (including shared decision making), anaemia and pain management.

We are also looking to promote positive stories from hospitals who are really engaging with enhanced recovery, whatever that means to them locally. And finally, we want to hear success stories about communication and engagement - this is at the centre of our realigned priorities for the coming year. All of the hospitals who provide us with these examples of improvement successes will be showcased next year so we really look forward to hearing your stories.

\section{Thank you}

It just remains for us to say thank you to the hundreds of collaborators and thousands of patients who have contributed to PQIP in 124 NHS hospitals so far. We think this is working. Please keep going and thank you again for your hard work and support.

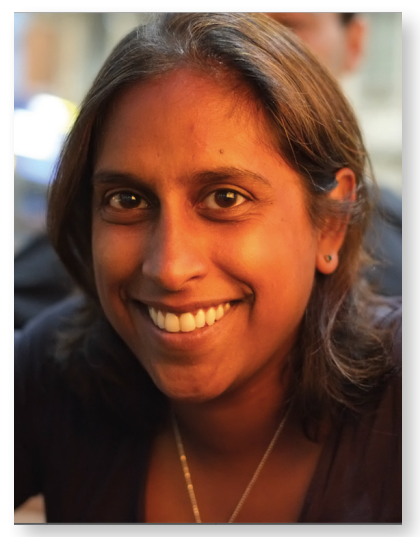

\author{
Ramani Moonesinghe \\ Chief Investigator, Perioperative Quality Improvement Programme \\ on behalf of the PQIP Project Team
}

Read our reports: www.pqip.org.uk

Follow us on Twitter: @PQIPNews

Join our team: pqip@rcoa.ac.uk 


\section{Top 5 National Improvement Priorities for 2019-20}

\section{Preoperative assessment}

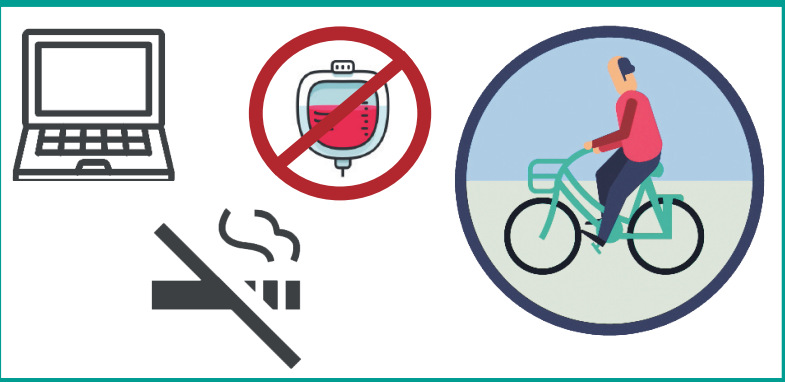

Individualised risk assessment

Anaemia detection \& treatment

Lifestyle and comorbidity optimisation

\section{Diabetes management}

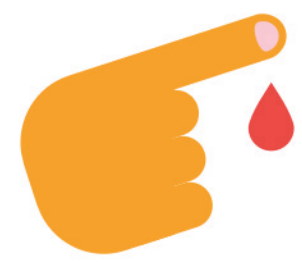

Measure $\mathrm{HbA} 1 \mathrm{C}$

Measure compliance against local pathway Restore usual nutrition as soon as possible

3 Communication and multidisciplinary working

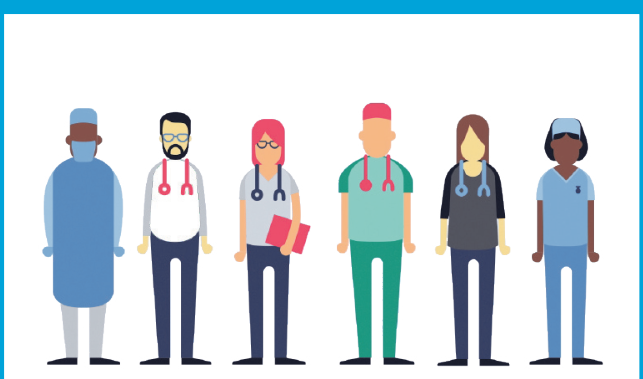

The whole MDT and patients can use PQIP to lead local improvement

Regular, multi-modal communication keeps PQIP in focus for the clinical team

Build discussion into clinical routines - team briefs, staff meetings, MDT meetings

Make your data work for you: use it to build business cases, support local reward systems etc.

4 Individualised pain management
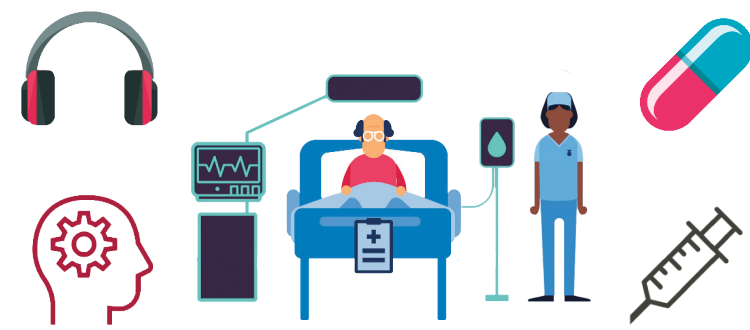

Expectation setting and management Multimodal analgesia

Local anaesthesia techniques

Distraction therapy

Regular, early post-op review by pain teams

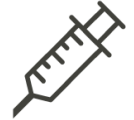

\section{Enhanced Recovery}
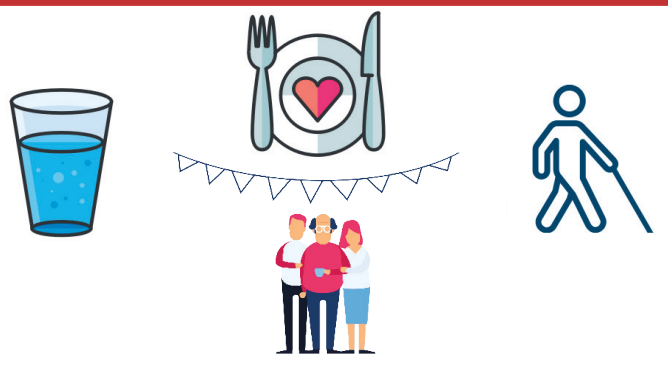

Surgery school or other tailored preparation

Pre-op nutritional assessment, carbohydrate loading and minimising starvation

Drinking, Eating (or nutritional supplementation) \& Mobilising within $24 \mathrm{~h}$

Minimise tubes, drains and 'institutionalisation' 


\section{PQIP sites and recruitment}

On 6 August 2019, 19,912 patients had been recruited into the PQIP patient study, of whom 18,530 had locked records. This report analyses data on those 18,530 patients.

\section{6,378 patients are categorised as 'Year 1' PQIP} patients - these are patients with a locked record who had surgery before 28 February 2018. This is a slightly larger number than recorded in last year's PQIP report, as a result of a few hundred late locked records being added to the Year 1 cohort. 12,152 patients are categorised as Year 2 PQIP patients.

It is great news that 124 hospitals in England and Wales are now recruiting patients to PQIP, up from 71 in Year 1. We hope that our first sites in Northern Ireland and Scotland will join soon!

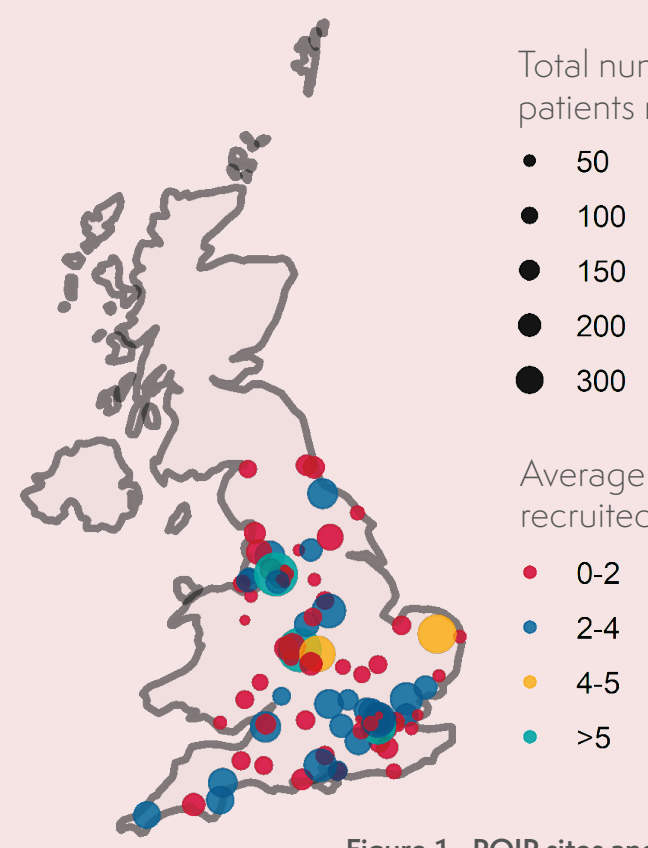

Figure 1. PQIP sites and recruitment

\section{Quality Accounts}

PQIP is now on the NHS England/Improvement (NHSE/I) Quality Accounts list, and the Getting It Right First Time Programme in perioperative care is also encouraging engagement with PQIP. We also remain a National Institute for Health Research (NIHR) portfolio adopted research study, which means that hospital Research \& Development departments receive support for research staffing from their local Clinical Research Network (CRN) as a result of recruiting patients to PQIP.

\section{Local support}

Despite all these incentives, on average, each hospital is recruiting fewer patients per week than in Year 1. We know that resources are limited and that PQIP teams are finding it difficult to secure help from their CRNs and R\&D departments. We have made our concerns known to the NIHR and will continue to work with you to increase recruitment for patient benefit.

The Lister Hospital is our top recruiting site for 2019, with an average of almost 8 patients per week over the 12 weeks that they had been recruiting! Our other top recruiting sites are listed below, and it's great to see such diversity in geography, hospital size and type. Some of these very high recruiting hospitals have involved trainees in recruiting patients as well as nurses. Get in touch with them to find out their secrets!

Birmingham Heartlands, St Georges, Salford Royal, Norfolk and Norwich, University Hospital Coventry, St James University Hospital, Nottingham City Hospital, University Hospital Wales, St Thomas Hospital
Figure 2. Recruitment by date

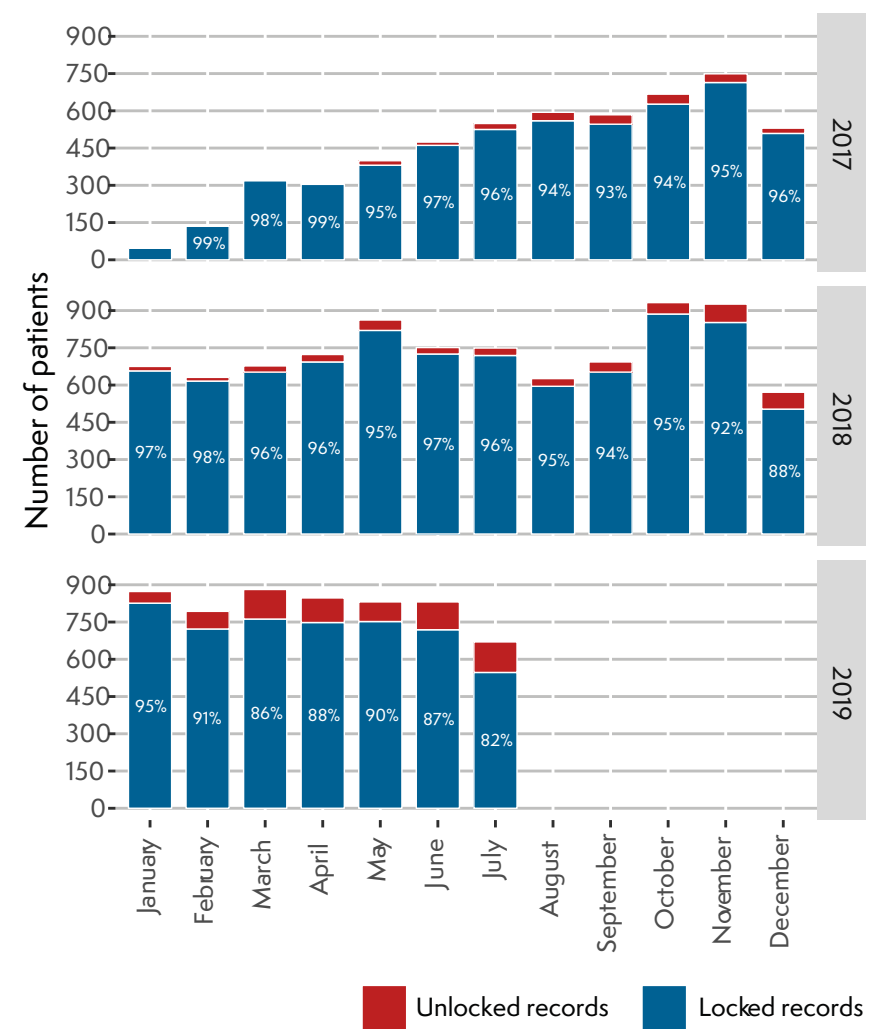




\section{What do PQIP patients look like?}

Y2 PQIP patients recruited from our original specialties of urology, head and neck, upper and lower Gl and thoracic surgery generally looked pretty similar to Y1 patients in terms of age, comorbidities, ASA grade, surgical magnitude and urgency. However, adding in complex orthopaedics, spinal, gynaecology and vascular surgery during Y2 has changed some aspects of the overall cohort profile, most notably that a smaller proportion have cancer.

\begin{tabular}{|c|c|c|}
\hline & Year $1(n=6,378)$ & Year $2(n=12,152)$ \\
\hline Age (median; IQR) & $67(57-73)$ & $66(55-73)$ \\
\hline Sex $(\%$ female) & 39 & 42 \\
\hline Body Mass Index (median; IQR) & $27(24-30)$ & $27(24-30)$ \\
\hline Current smoker $(\%)$ & 11 & 10.4 \\
\hline \multicolumn{3}{|l|}{ ASA grade $(\%)$} \\
\hline - 1 & 10.9 & 11.1 \\
\hline$\cdot 2$ & 60.9 & 60.9 \\
\hline . 3 & 27 & 27 \\
\hline . 4 or 5 & 1.2 & 1.1 \\
\hline \multicolumn{3}{|l|}{ Surgical complexity $(\%)$} \\
\hline · $\quad$ Major & 13.4 & 11.6 \\
\hline - X-Major & 34.0 & 33.2 \\
\hline - Complex & 52.6 & 55.1 \\
\hline \multicolumn{3}{|l|}{ Surgical urgency $(\%)$} \\
\hline - $\quad$ Elective & 88.8 & 90.4 \\
\hline - Expedited & 11.2 & 9.6 \\
\hline \multicolumn{3}{|l|}{ Cancer diagnosis within 5 years (\%) } \\
\hline - None & 23.4 & 30.3 \\
\hline - Solid tumour, no metastasis & 59.1 & 54.4 \\
\hline - Solid tumour with metastasis & 17.5 & 15.2 \\
\hline · $\quad$ Leukaemia & 0.3 & 0.2 \\
\hline - Lymphoma & 0.5 & 0.4 \\
\hline \multicolumn{3}{|l|}{ Diabetes $(\%)$} \\
\hline - None & 87.3 & 86.8 \\
\hline • $\quad$ Type 1 & 0.7 & 0.7 \\
\hline - Type 2 diet controlled & 2.8 & 3.1 \\
\hline - Type 2 oral hypoglycemics & 6.6 & 6.6 \\
\hline - Type 2 with insulin & 2.6 & 2.8 \\
\hline \multicolumn{3}{|l|}{ NYHA Heart Failure Class $(\%)$} \\
\hline · 1 & 83.0 & 82.7 \\
\hline$\cdot 2$ & 14.2 & 14.7 \\
\hline$\cdot 3$ & 2.6 & 2.5 \\
\hline - 4 & 0.2 & 0.1 \\
\hline \multicolumn{3}{|l|}{ Other co-morbidities } \\
\hline Respiratory history $(\%)$ & 15.6 & 14.6 \\
\hline Acute respiratory infection within past month (\%) & 4 & 3.3 \\
\hline Abnormal ECG $(\%)$ & 14.6 & 15.3 \\
\hline Cerebrovascular disease $(\%)$ & 4.0 & 4.1 \\
\hline Dementia $(\%)$ & 0.6 & 0.8 \\
\hline Liver disease (\%) & 1.3 & 1.1 \\
\hline
\end{tabular}




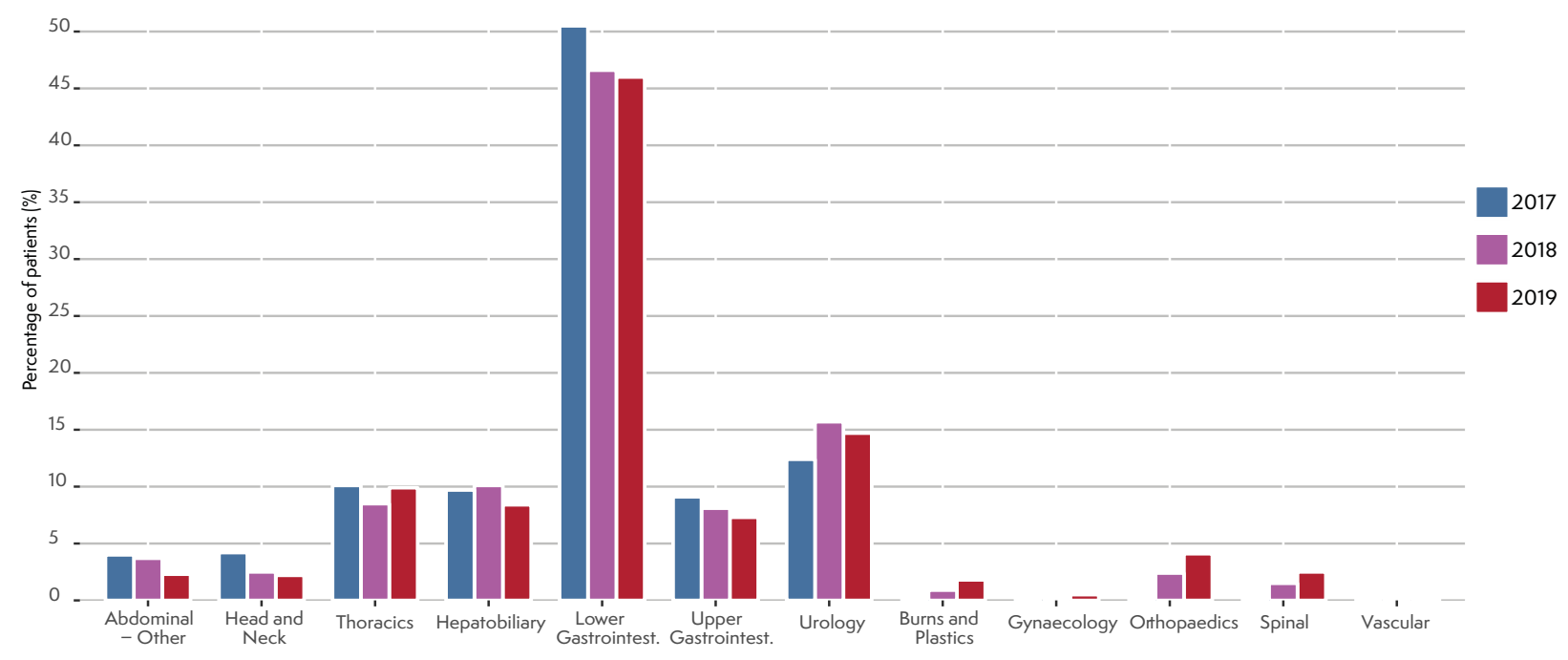

Figure 3. Patient recruitment by surgical specialty

Our patients are having complex operations - 68\% had surgery lasting more than 3 hours (69\% last year); $99 \%$ had surgery under the direct supervision of a consultant surgeon and $96 \%$ under the direct supervision of a consultant anaesthetist. $41 \%$ of patients are admitted to Level 2 or 3 (critical care) after their operation.

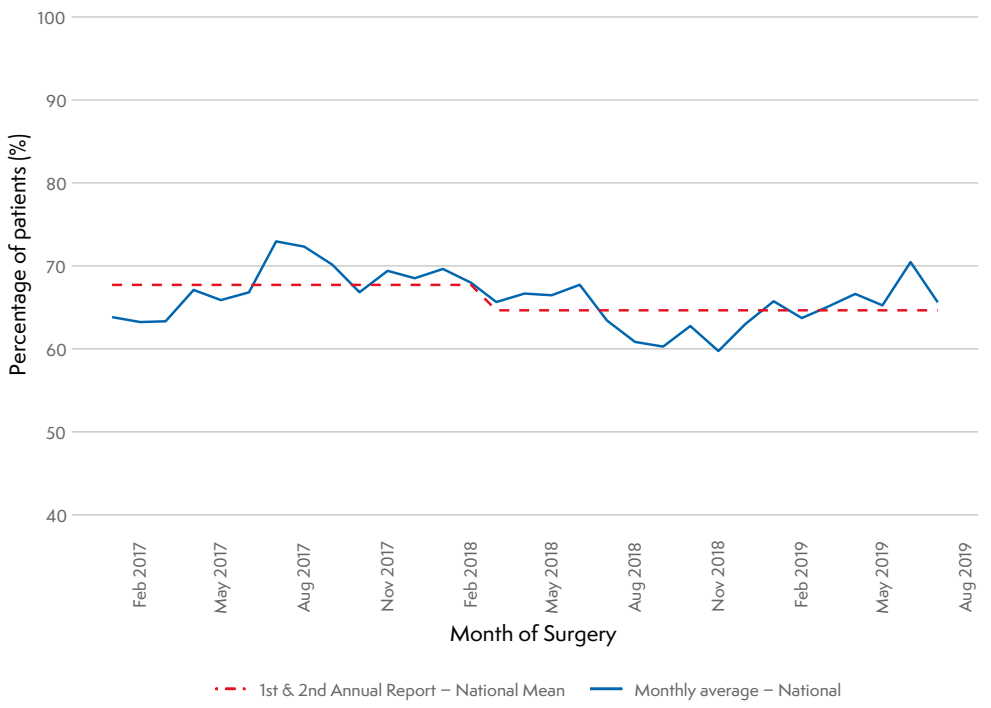

Figure 4. Patients with documented individualised risk assessment

\section{Individualised risk assessment and ICU admission}

$65 \%$ of patients had a documented individualised risk assessment in $\mathrm{Y}$, compared with 68\% in Y1. We had hoped to push towards 100\% this year so we're keen to understand the challenges to this locally. This may be impacting on patient care: $31 \%$ of patients with a greater than $5 \%$ risk of 30 day mortality are admitted to a normal ward after surgery.

A closer look at the data shows that within colorectal, upper $\mathrm{Gl}$ and urology there has been a modest improvement in individualised risk assessment rates, but this has been offset by other specialties all getting worse. Compliance with this goal is particularly low in our new specialties and in hospitals which started PQIP in Y2 the hospitals which started in $Y 1$ have actually got a bit better).

\section{What next for local teams?}

This should be a relatively straightforward goal for local teams. It should also be a governance priority, in light of the Montgomery ruling, so this might be one for managers to get involved with as well. This is one of the metrics which has been a consistent improver in the National Emergency Laparotomy Audit, so it might be worth looking across the corridor to see how your NELA teams have approached the issue locally.

\section{How can we help?}

We want to generate healthy competition without hospitals worrying about being exposed as 'poor performers'. So we're creating toolkits and launching national competitions to encourage teams to develop and share improvement projects addressing these tricky problems with the rest of the PQIP community (see page 3). 


\section{A bit stuck... where haven't things improved?}

There are a few measures on which we haven't done as well as we hoped to this year.

Figure 5. Patients with HbA1C measurement

\section{HbA1C measurement}

Like in Year 1, 13\% of PQIP patients were diabetic. We aimed to measure $\mathrm{HbA} 1 \mathrm{C}$ in $100 \%$ of diabetic patients this year. We're a little better than last year (72\% of patients tested vs. 69\% in Year 1$)$ and our chart shows that things seemed to improve since last year's recommendations came out, but we're still a long way off where we want to be.

\section{What next for local teams?}

- Even if you're doing well on this, check your data. The HbA1C should have been done within 3 months of surgery

- Have a look at a convenience sample of 100

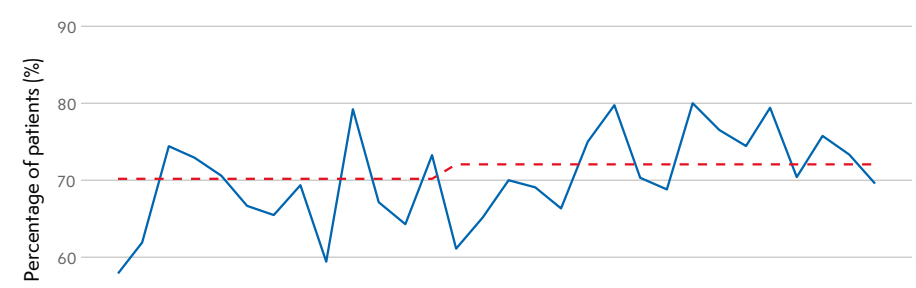
patient notes (say 5 or 10) where the HbA1C wasn't done. Were there any obvious issues: e.g. late referrals, late preoperative assessment, external referral from another hospital...?

- Remember, HbA1C measurement is just the first step in a pathway of good diabetes management. How are you doing against the national guidelines? In your convenience sample, check compliance with best practice in perioperative diabetes management. Did they have blood sugar measurement done, documented and appropriately acted upon throughout their inpatient stay?

\section{Anaemia management}

Despite anaemia management being on our top 5 priority list last year, we haven't seen a major change in anaemia rates. There has been a very modest improvement in the proportion of patients with moderate or severe anaemia (11.6\% in $\mathrm{Y} 1$ and $10.4 \%$ in $\mathrm{Y} 2$ ) but still around $11 \%$ of patients with anaemia incur an intraoperative blood loss of more than $500 \mathrm{ml}$. More women than men have moderate or severe anaemia.

We recently started collecting data on how preoperative anaemia is (or isn't) being managed. So far, we've found that almost $70 \%$ of patients with $\mathrm{Hb}<130 \mathrm{~g} / \mathrm{l}$ did not receive any treatment for anaemia in the 3 months before surgery. This looks like another real opportunity for improvement.

\section{What do we need to do?}

Anaemia pathways which enable patients to have rapid access to IV iron therapy where required are increasingly common. Don't forget the international consensus guidelines state that both men and women should have a target pre-op Hb of at least $130 \mathrm{~g} / \mathrm{l}$ before major surgery where a blood loss of $>500 \mathrm{ml}$ might be anticipated. Check out our anaemia guide at www.paip.org.uk for more tips on what to do next.

\section{Sharing data and ideas to support local improvement}

\section{STAR trainee network, Severn region}

Sharing of PQIP data across the STAR (Severn Trainee Anaesthetic Research) trainee research network in Severn has helped identify opportunities to improve management of pre-operative anaemia. Hospitals willingly shared their PQIP data which highlighted identified differences in pathways. This has given an opportunity for standardisation of processes and improvement across the region. 


\section{Living the DrEaM}

One of PQIP's big successes this year is the improvement in patients who are 'living the dream' - Drinking, Eating and Mobilising within $24 \mathrm{~h}$ of surgery ending. Not only have the national figures improved in almost every specialty, but individually, the majority of hospitals are also improving their performance.

\section{What are we learning?}

DrEaMing is a straightforward improvement opportunity to communicate and target. Even where there is some controversy, e.g. early oral intake in upper $\mathrm{Gl}$ surgery, improvements have been made in mobilisation. The exception is head and neck and we'll work with the small number of teams recruiting patients in this specialty to understand their data better.

\section{What next for local teams?}

Let's keep going! In most specialties, there is still opportunity to improve further. Take a look at your local data to see how you're doing. The PQIP team also need to learn from this experience and think about crafting all our improvement priorities in a similarly succinct, easily communicable way. More on this in our infographics available at www.paip.org.uk.

Tables 2-8. Percentage of patients DrEaMing in PQIP specialties

\begin{tabular}{|l|l|l|}
\hline Urology & Year $\mathbf{1} \% \mathbf{( n = 8 7 0 )}$ & Year $\mathbf{2} \%(\mathbf{n}=\mathbf{1 , 7 5 1 )}$ \\
\hline Drinking * & 92 & 95 \\
\hline Eating * & 74 & 82 \\
\hline Mobilising * & 80 & 85 \\
\hline DrEaMing * & 65 & 74 \\
\hline
\end{tabular}

\begin{tabular}{|l|l|l|}
\hline Colorectal & Year $\mathbf{1} \%(\mathbf{n}=\mathbf{3 , 2 0 0})$ & Year $\mathbf{2} \%(\mathbf{n}=\mathbf{5 , 3 9 0 )}$ \\
\hline Drinking * & 85 & 92 \\
\hline Eating & 64 & 66 \\
\hline Mobilising & 79 & 80 \\
\hline DrEaMing & 56 & 57 \\
\hline
\end{tabular}

\begin{tabular}{|l|l|l|}
\hline Upper GI & Year 1 \% (n= 572) & Year 2\% (n= 905) \\
\hline Drinking & 33 & 37 \\
\hline Eating & 14 & 18 \\
\hline Mobilising * & 55 & 61 \\
\hline DrEaMing & 13 & 16 \\
\hline
\end{tabular}

\begin{tabular}{|l|l|l|}
\hline HPB & Year $\mathbf{1} \%(\mathbf{n}=\mathbf{6 0 3})$ & Year $\mathbf{2} \%(\mathbf{n}=\mathbf{1 , 1 2 2})$ \\
\hline Drinking * & 69 & 76 \\
\hline Eating & 47 & 52 \\
\hline Mobilising & 66 & 64 \\
\hline DrEaMing & 38 & 43 \\
\hline
\end{tabular}

\begin{tabular}{|l|l|l|}
\hline Head and Neck & Year 1\% (n= 256) & Year 2\% (n= 267) \\
\hline Drinking & 50 & 46 \\
\hline Eating & 41 & 41 \\
\hline Mobilising & 75 & 68 \\
\hline DrEaMing & 40 & 39 \\
\hline
\end{tabular}

\begin{tabular}{|l|l|l|}
\hline Abdominal - other & Year 1 \% (n= 247) & Year $\mathbf{2} \%(\mathbf{n}=\mathbf{3 6 7})$ \\
\hline Drinking * & 68 & 87 \\
\hline Eating * & 47 & 61 \\
\hline Mobilising * & 68 & 76 \\
\hline DrEaMing * & 40 & 54 \\
\hline
\end{tabular}

\begin{tabular}{|l|l|l|}
\hline Thoracics & Year $\mathbf{1} \%(\mathbf{n}=\mathbf{6 3 0})$ & Year $\mathbf{2} \%(\mathbf{n}=\mathbf{1 , 0 5 0})$ \\
\hline Drinking * & 93 & 98 \\
\hline Eating * & 93 & 96 \\
\hline Mobilising * & 90 & 95 \\
\hline DrEaMing * & 85 & 92 \\
\hline
\end{tabular}

Table 9. Percentage of patients DrEaMing in new PQIP specialties

\begin{tabular}{|l|l|l|l|l|l|}
\hline & $\begin{array}{l}\text { Orthopaedics \% } \\
(\mathbf{n}=\mathbf{5 8 2})\end{array}$ & $\begin{array}{l}\text { Spinal \% } \\
(\mathbf{n}=\mathbf{3 6 7 )}\end{array}$ & $\begin{array}{l}\text { Burns and Plastics\% } \\
(\mathbf{n}=\mathbf{2 4 2})\end{array}$ & $\begin{array}{l}\text { Gynaecology \% } \\
(\mathbf{n}=\mathbf{7 5})\end{array}$ & $\begin{array}{l}\text { Vascular \% } \\
(\mathbf{n}=\mathbf{3 4})\end{array}$ \\
\hline Drinking & 99 & 98 & 100 & 95 & 97 \\
\hline Eating & 97 & 96 & 97 & 92 & 91 \\
\hline Mobilising & 65 & 73 & 85 & 91 & 77 \\
\hline DrEaMing & 65 & 72 & 84 & 87 & 71 \\
\hline
\end{tabular}




\section{Morbidity, complications and length of hospital stay}

We're really delighted to report that major morbidity has fallen between $Y 1$ and $Y 2$. Here we present a comparison of Y1 and Y2 outcomes. Some of our new specialties have lower morbidity rates so the final column shows Y2 outcomes in only our original PQIP specialties of GI, HPB, urology, head and neck and thoracic surgery.

\section{Morbidity}

\begin{tabular}{|c|c|c|c|c|c|}
\hline Day 7 morbidity domain & $\begin{array}{l}\text { Year } 1 \% \\
(n=6,378)\end{array}$ & $\begin{array}{l}\text { Year } 2 \% \\
(n=12,152)\end{array}$ & Day 7 morbidity domain & $\begin{array}{l}\text { Year } 1 \% \\
(n=6,378)\end{array}$ & $\begin{array}{l}\text { Year } 2 \text { excluding new } \\
\text { specialties } \%(n=10,852)\end{array}$ \\
\hline Major pulmonary* & 6.2 & 5.3 & Major pulmonary & 6.2 & 5.8 \\
\hline Major infection* & 12.8 & 11.5 & Major infection & 12.8 & 12.2 \\
\hline Major renal* & 1.5 & 1.1 & Major renal & 1.5 & 1.2 \\
\hline Major cardiac* & 2.7 & 2.2 & Major cardiac & 2.7 & 2.4 \\
\hline Major neurological" & 2.4 & 1.8 & Major neurological* & 2.4 & 1.8 \\
\hline Major wound* & 4.5 & 3.2 & Major wound* & 4.5 & 3.4 \\
\hline Major haematological & 0.8 & 0.8 & Major haematological & 0.8 & 0.8 \\
\hline Major pain & 0.9 & 0.8 & Major pain & 0.9 & 0.9 \\
\hline All gastrointestinal * & 14.9 & 11.8 & All gastrointestinal * & 14.9 & 13.0 \\
\hline Any morbidity* & 28.4 & 23.8 & Any morbidity" & 28.4 & 25.1 \\
\hline Any major morbidity* & 18.7 & 16.4 & Any major morbidity* & 18.7 & 17.2 \\
\hline
\end{tabular}

Table 10. Major postoperative morbidity $¥$ on day 7 after surgery

$¥$ measured using the POMS major definition which includes any type of POMS defined morbidity of $\geq$ Clavien-Dindo level 2. For Gastrointestinal morbidity, as all definitions are Clavien Dindo level 1 we have shown all morbidity rather than just major. For more information see Grocott et al, 2007: I Clin Epi. 60; 917. 928 and Wong et al, 2017: Brit J Anaes. 119 (1); 95-105.

By far the most common major morbidity is infection, with more than 1 in 10 patients remaining in hospital on day 7 either on IV antibiotics or with a temperature of $>38$ degrees in the previous $24 \mathrm{~h}$.

\section{Postoperative length of stay}

It is also great news that we have seen a fall in postoperative length of stay overall for PQIP patients this year, and in almost every specialty individually. The improvement in length of stay was particularly good in hospitals which have been taking part in the study for the longest period of time.

\begin{tabular}{|l|l|l|l|l|}
\hline & Year $\mathbf{1}(\mathbf{n})$ & $\begin{array}{l}\text { Mean length of } \\
\text { stay (days) }\end{array}$ & Year $\mathbf{~ ( n ) ~}$ & $\begin{array}{l}\text { Mean length of } \\
\text { stay (days) }\end{array}$ \\
\hline Urology* & 870 & 6.2 & 1751 & 5.2 \\
\hline Upper gastrointestinal & 572 & 13.4 & 905 & 12.9 \\
\hline Lower gastrointestinal* & 3200 & 8.9 & 5390 & 8.5 \\
\hline Hepatobiliary & 603 & 9.6 & 1122 & 9.8 \\
\hline Thoracics & 630 & 5.3 & 1050 & 4.8 \\
\hline Head and Neck* & 256 & 12.7 & 267 & 10.3 \\
\hline Abdominal - other & 247 & 11 & 367 & 10.1 \\
\hline Orthopaedics & - & - & 582 & 8.8 \\
\hline Spinal & - & - & 367 & 4.9 \\
\hline Burns and Plastics & - & - & 242 & 5.1 \\
\hline Gynaecology & - & - & 75 & 3 \\
\hline Vascular & - & - & 34 & 4.9 \\
\hline
\end{tabular}




\begin{tabular}{|l|l|l|l|l|}
\hline & Year $\mathbf{1}(\mathbf{n})$ & Length of stay (days) & Year $\mathbf{2}(\mathbf{n})$ & Length of stay (days) \\
\hline Total PQIP population & 6378 & 8.9 & 12152 & 8.0 \\
\hline Hospitals participating in both Y1 and Y2 $(n=65)$ & 6378 & 8.9 & 8835 & 7.8 \\
\hline
\end{tabular}

Table 12. Length of stay between years 1 and 2 for entire PQIP cohort $(n=18,530)$

But as you can see from the graphs below, the impact of major complications (defined as requiring a Clavien-Dindo grade 3 or above intervention) on length of stay remains very substantial across the board.

Year 1

Figure 6. PQIP Year 1

Clavien-Dindo scores and mean length of stay

\author{
Abdominal - Other \\ Head and Neck \\ Thoracics \\ Hepatobiliary \\ Lower Gastrointestinal \\ Upper Gastrointestinal
}

Urology

Abdominal - other
Head and neck

Thoracics

Hepatobiliary

Lower gastrointestinal

Upper gastrointestinal

Urology

Burns and Plastics

Gynaecology

Orthopaedics

Spinal

Figure 7. PQIP Year 2

Clavien-Dindo scores and mean length of stay
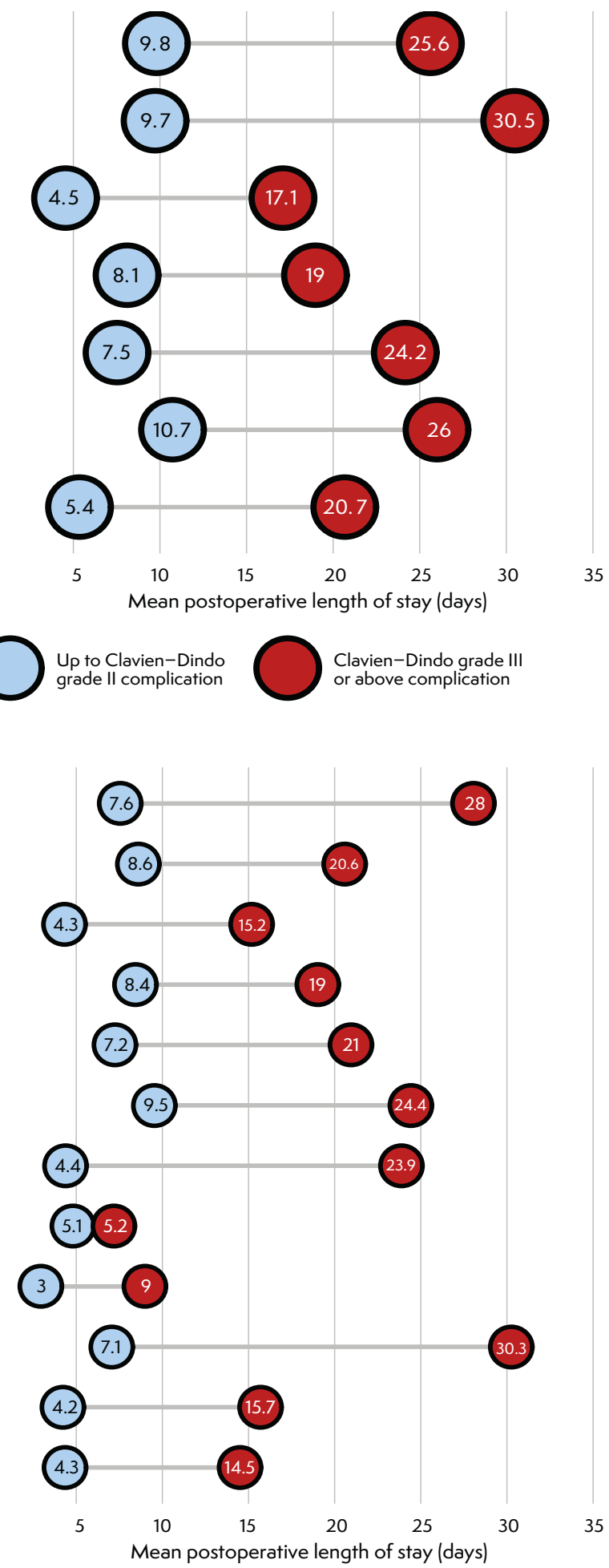


\section{Individualised pain management}

We're a bit stuck on our pain outcomes. Including all Y1 and Y2 data, 7.5\% of patients reported severe pain in recovery and $19.8 \%$ reported severe pain within 24 h of surgery (on the Baver patient satisfaction questionnaire).

The key findings from pain data:

- There is a huge increase in the proportion of patients experiencing severe pain between recovery and at 24h in almost all specialties apart from head and neck surgery

- Recovery room pain is highest in upper Gl, hepatobiliary and head and neck surgery

- Around $20 \%$ of PQIP patients have no short-term (recovery room) pain data recorded.

\begin{tabular}{|l|l|l|l|l|l|}
\hline Year 1 & Recovery $(\boldsymbol{\%})$ & $\mathbf{2 4 h}(\boldsymbol{\%})$ & Year 2 & Recovery $(\boldsymbol{\%})$ & $\mathbf{2 4 h}(\mathbf{\%})$ \\
\hline Urology & 6.8 & 15.7 & Urology & 5.5 & 20.4 \\
\hline Upper gastrointestinal & 11.5 & 14.9 & Upper gastrointestinal & 16.5 & 19.6 \\
\hline Lower gastrointestinal & 5.3 & 20.5 & Lower gastrointestinal & 5.6 & 18.6 \\
\hline Hepatobiliary & 8.6 & 16.9 & Hepatobiliary & 13.1 & 17.6 \\
\hline Abdominal-other & 10.9 & 26.8 & Abdominal-other & 7.6 & 21 \\
\hline Thoracics & 6.3 & 27 & Thoracics & 6.3 & 24.3 \\
\hline Head and Neck & 24.2 & 14.3 & Head and Neck & 20.6 & 15.8 \\
\hline Orthopaedics & - & - & Orthopaedics & 5.2 & 28 \\
\hline Spinal & - & - & Spinal & 9.0 & 24.2 \\
\hline Burns and Plastics & - & - & Burns and Plastics & 3.7 & 13.2 \\
\hline
\end{tabular}

Table 13. Percentage of patients reporting severe pain in recovery and within $24 \mathrm{~h}$

We start to see some really fascinating patterns when looking at patients who have had different types of intraoperative analgesia/anaesthesia and their pain outcomes. Take a look at this:

\begin{tabular}{|c|c|c|}
\hline & Severe recovery pain $(\%)$ & Severe pain within $24 \mathrm{~h}(\%)$ \\
\hline GA only & 11.3 & 22.0 \\
\hline \multicolumn{3}{|l|}{ Local/regional } \\
\hline LA infiltration only & 4.3 & 20.4 \\
\hline Regional block & 5.7 & 23.1 \\
\hline \multicolumn{3}{|l|}{ Neuraxial } \\
\hline Epidural & 7.5 & 16.8 \\
\hline CSE & 0 & 17.1 \\
\hline Spinal & 5.5 & 17.9 \\
\hline
\end{tabular}

\section{What does this all mean?}

The key message we get from this is that where general anaesthesia is topped up with additional local, regional or neuraxial blockade, pain outcomes in recovery are pretty good - however, across the board, around 1 in 5 patients are experiencing severe pain within $24 \mathrm{~h}$ of surgery. So we perhaps need to switch focus to those crucial first $24 \mathrm{~h}$ after surgery when we want patients to be really comfortable so that they can start drinking, eating, mobilising and generally recovering from their major surgery.

\section{What next for local teams?}

We think this is a target for improvement. 1 in 5 patients having severe pain at 24h seems high to us and we think we should try to improve. Reasons for this will vary locally but things for teams to look at are highlighted in our pain management guide. 


\section{Patient satisfaction and comfort}

The Baver patient satisfaction score for patient reported outcome within $24 \mathrm{~h}$ continues to point towards successes and opportunities for improvement. We're delighted that PQIP data have prompted some trusts into action about some of the commonest types of postoperative discomfort, like thirst, sore throat and hoarseness (plus we're also delighted to see such a great improvement in drinking rates within 24h of surgery - see page 9).

But we still have a lot to do to improve short-term patient experience overall in our high-risk cohort. In particular, postoperative nausea and vomiting remains a significant problem for $8 \%$ of patients, and we know from other studies that this has a big impact on patients.

\section{Using your data for local QI projects}

Two PQIP hospitals have used their patient satisfaction data to develop QI projects aimed at improving postoperative patient experience! See below land also our cover to see the POM-POPs team with their lollipops!) for more, and consider how you could use your own local data to drive improvement.
Figure 8. Patient experience of anaesthetic-related discomfort (Bauer patient satisfaction score)

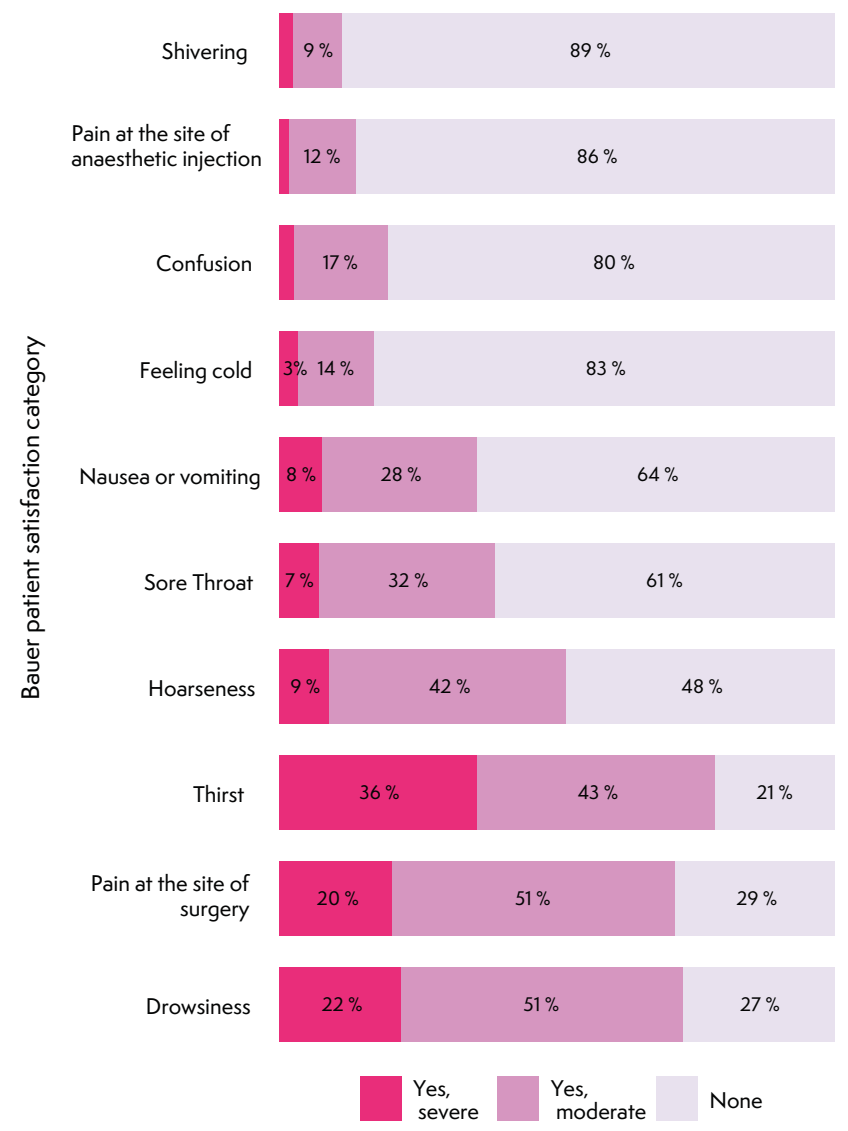

Oh, we do love to be beside the seaside....

\section{Dr Mark Paul, Clinical Director, Brighton and Sussex University Hospital}

We tried to get ice lollies in recovery some time ago. We'd seen a small study showing a possible anti-emetic effect and it just seemed like a nice thing to offer someone after an operation. Unfortunately, there were a few annoying, in-hospital barriers to this and we never quite got there. When we started collecting PQIP data we could see that thirst, sore throat and hoarseness immediately post-operatively were significant issues so we tried again to get the ice lollies and our persistence has now paid off. We'll be using PQIP data to measure any improvement but anecdotally they've been a great success so far and we're having to buy a bigger freezer to cope with the increasing demand!

\section{POM-POPS - a different airline industry analogy}

\section{Prof David Walker, Clinical Lead for the Post-Anaesthetic Care Unit, UCLH at Westmoreland Street}

Learning from the work of a flight attendant preparing a business class traveller for an overnight transatlantic flight might be a good analogy. Fed, watered, bed-comfortable, lights down, ear plugs in and eye-shields on, good book and the occasional glass of something medicinal might be all that is needed to improve the patient journey.

We may think we do that already, but it's amazing what you find out when you really ask the patient. POM-POPS are our in-house solution to the common problem of postoperative thirst, lollipops made in our kitchens and offered liberally to our patients. They are a critical part of our new 'comfort rounds' which involve nurses and doctors rounding together and exploring what matters to patients, attempting to reduce anxiety, and pain, improve sleep and consider changes to the ward environment and the daily routine. PQIP data, particularly from the Baver patient satisfaction questionnaire, will help us monitor how we're doing and focus. 


\section{Longer-term patient reported outcomes}

One of the jewels in the crown of the PQIP database is the longer-term patient reported outcome (PROMs) data. We are collecting several PROMs measures, including the Euro-Quality of Life (Euro-QOL) EQ5D measure and the World Health Organisation's Disability Assessment Schedule. Here we are able to present some snapshots of PROMs data, really just as a thank you to teams and patients for working together to collect this information, and as a 'teaser' for how we hope to use this information in the future. These graphs show the change in different measures of the EQ5D questionnaire between admission and 6 months. We have only included specialty-specific data for those groups with more than 500 patients reporting both baseline and 6 month outcomes. On the next page, we have alluvial plots for all PQIP patients who responded to the baseline and 6 month questionnaires. These demonstrate the trajectory for individual patients for the five different EQ5D domains.

Figure 9. All PQIP patients

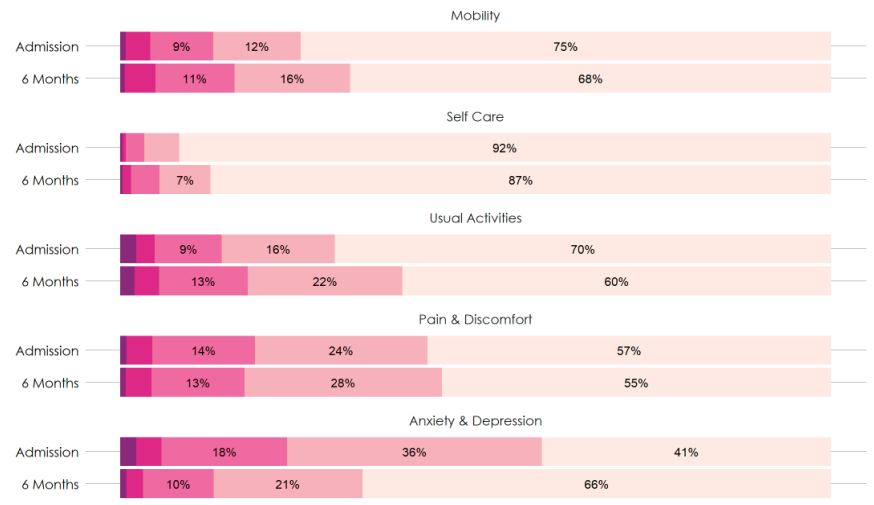

Figure 11. Upper GI

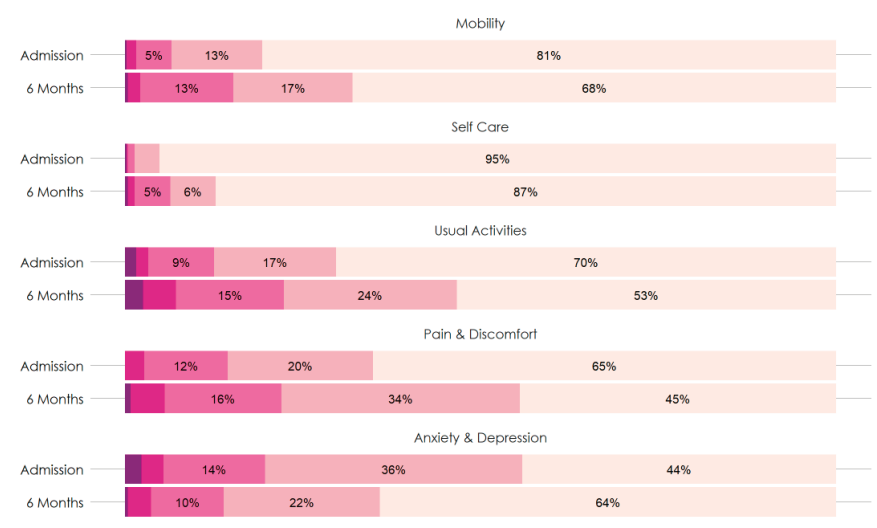

Figure 10. Urology

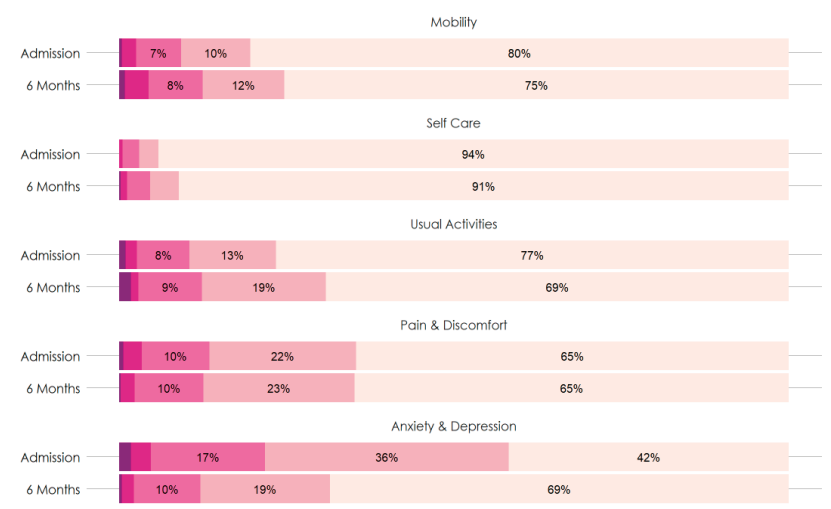

Figure 12. Lower GI

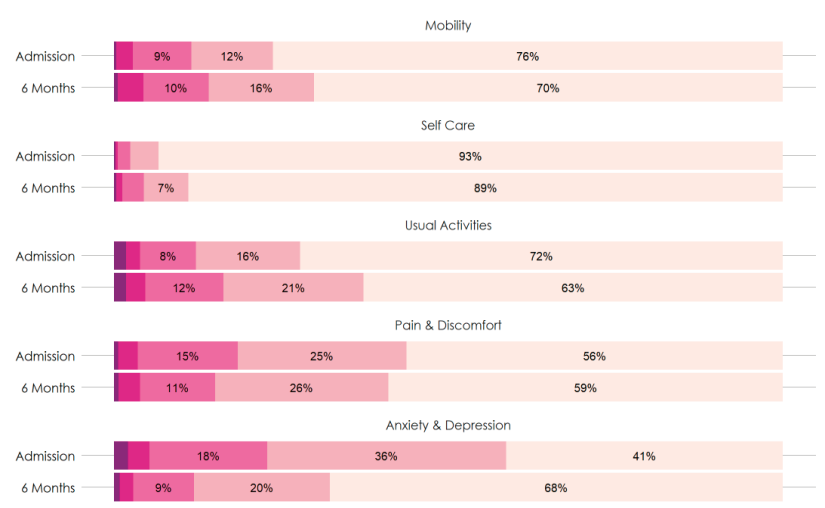

Severity No Problem Mild

\section{What does this all mean?}

Perhaps unsurprisingly, in the run up to major surgery, anxiety and depression is an issue for around 60\% of PQIP patients. While this improves for many by 6 months, over $40 \%$ of patients still have some problems. The proportion of patients who report moderate, severe or extreme pain is similar at 6 months to baseline, but the alluvial charts on page 15 show significant numbers of individual patients who both improve and deteriorate from a pain perspective. Looking in more detail at each of these groups to identify whether there are any potentially modifiable factors which can reduce the risk of significant pain at 6 months will be a priority going forward.

\section{What next for local teams?}

At this stage, these data are provided more for interest than as a target for improvement. But, given the importance of mental health for physical recovery, looking at your PQIP data prospectively to identify patients who report that they are feeling anxious or depressed, and working across the multidisciplinary team to ensure that they have the psychological support that they need lincluding collaborating with primary care, nurse specialists, Macmillan teams and so on as relevant) would be a great patient-centred Ql goal. 


\section{Figure 13. Mobility}

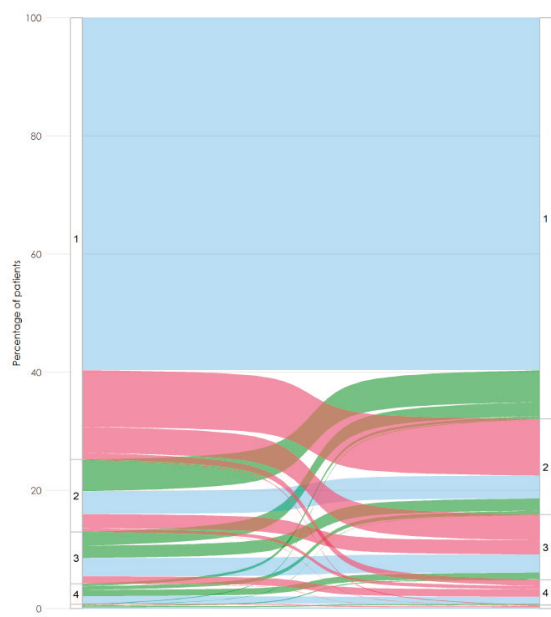

Figure 16. Self-care

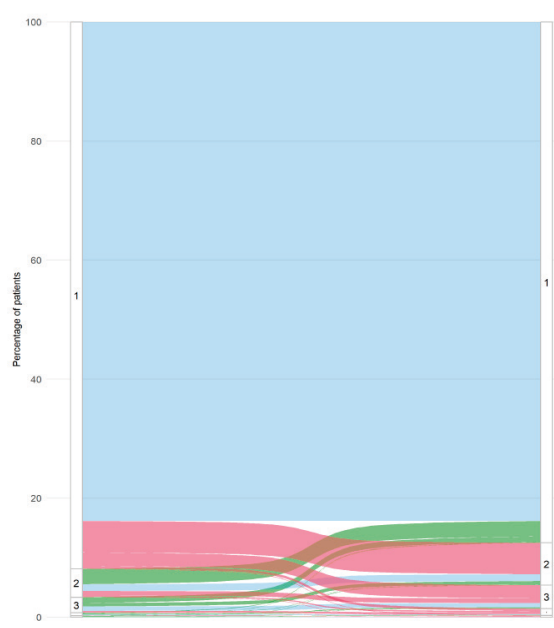

Figure 14. Usual activities

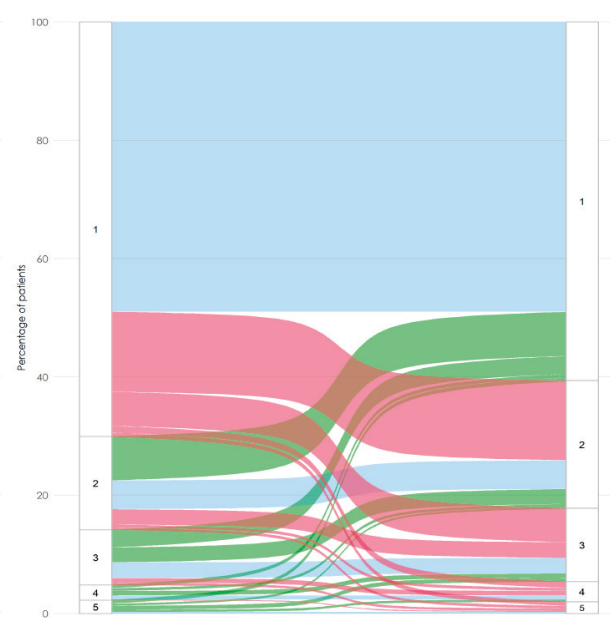

Figure 17. Anxiety and depression

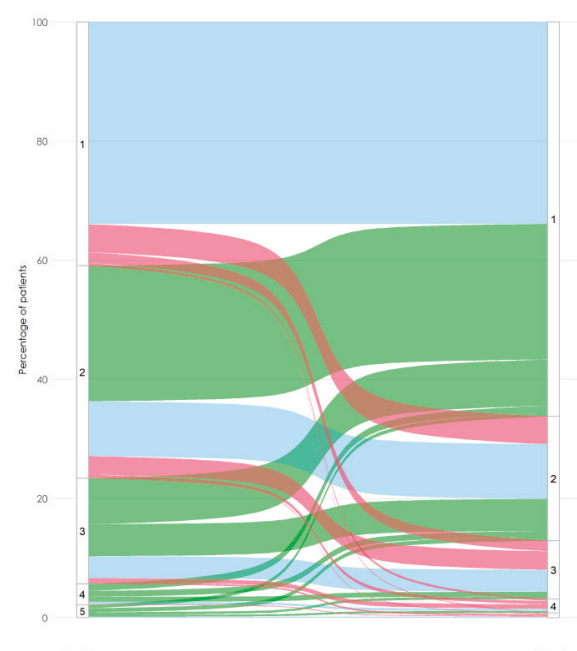

Figure 15. Pain and discomfort

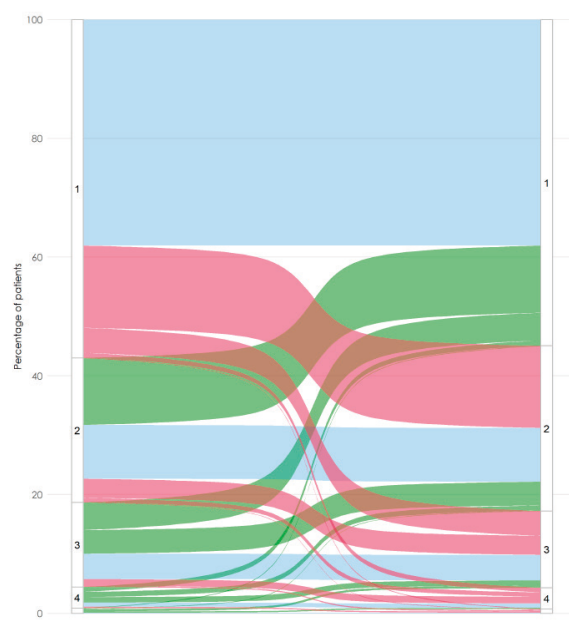

Change in domain level from admission to 6 months postoperatively

Deterioration
No change
Improvement

$1=$ No problem

2 = Slight problem

$3=$ Moderate problem

$4=$ Severe problem

$5=$ Unable/extreme

\section{Engaging staff, engaging patients, improving data collection and completion}

We know that data collection for PQIP is a burden on local teams and we are really grateful to you for your efforts and we hope you can see the value of this information. Phone follow-up tends to have better success rates than email - we are finding this in PQIP and this is well documented in the literature. Some hospitals with really great data completion and follow-up rates have shared their secrets with us...

St James' University Hospital has improved contemporaneous data collection with drop in sessions in theatre complete with PQIP cakes as incentives! They've marked the notes with a PQIP stamp and study number. Use of the NHS messaging app allows notification of anaesthetists and QI leads.

University Hospital Wales has also used messaging to co-ordinate data collection, they use WhatsApp to highlight upcoming patients and follow-ups using only non-identifiable data. They have found that use of live messaging has created a 'buzz' within the team where everyone can see how hard other members are working.

Please note that PQIP does not endorse any specific messaging service. If you are going to use live messaging services to communicate about PQIP patients, please do take note of the NHS guidance for this: https://bit.ly/2AU/ZOO. 


\section{Celebrating success - the positive deviance lists!}

Here we list the hospitals which are doing particularly well at various measures and have met or exceeded our national target for each process. Please note we have only listed hospitals who recruited at least 50 patients in Y2. We're thrilled that we've had to reduce our font size compared to last year's report! These lists tell us that great things are possible in lots of places - so we continue to aim to achieve these goals everywhere. Congratulations to all teams featured here!

Anaemia management: National target $>80 \%$ of patients having elective surgery with pre-op $\mathrm{hb} \geq 13$

In these hospitals, $>80 \%$ of male patients having elective surgery had Hb $\geq 13$ : Lister Hospital, Royal National Orthopaedic Hospital, Royal Preston Hospital

In these hospitals, $>80 \%$ of patients who had elective surgery and blood loss $>500 \mathrm{ml}$ started with $\mathrm{Hb}>13$ : Royal Liverpool University Hospital, Royal National Orthopaedic Hospital, Southampton General Hospital, St Thomas' Hospital, Royal Marsden Hospital

\section{Diabetes (HbA1C measurement): National target 100\%}

These hospitals recruited at least 5 patients with diabetes and recorded $\mathrm{HbA} 1 \mathrm{C}$ in $\mathbf{1 0 0 \%}$ of those patients: Countess of Chester, Darent Valley, East Surrey, Hereford County, King's Mill, Nevill Hall, Northampton General, Royal Berkshire, Royal Preston, Southmead, Stoke Mandeville, Tameside General

Individualised risk assessment: National target $>80 \%$ Aintree University Hospital, Basildon University Hospital, Bristol Royal Infirmary, Broomfield, Churchill, Cumberland Infirmary, Great Western, King's College Hospital (Denmark Hill), King's Mill Hospital, Lister, Nevill Hall, Papworth, Princess of Wales, Queen Elizabeth University Hospital, Gateshead, Royal Berkshire, Royal Blackburn, Royal Bournemouth, Royal Derby, Royal Lancaster Infirmary, Royal Preston, Sandwell General, Southampton General, St. Peter's, Sunderland Royal, Tameside General, Royal Marsden, The Royal Orthopaedic Hospital, Torbay Hospital, University Hospital Coventry, York Hospital

\section{Carbohydrate loading: National target $>80 \%$}

These hospitals gave $>\mathbf{8 0} \%$ of all their PQIP patients preoperative carbohydrate loading: Bristol Royal Infirmary, Countess of Chester, Great Western Hospital, King's Mill, Queen Elizabeth Hospital Birmingham, Queen Elizabeth University Hospital Gateshead, Queen Victoria Hospital, Royal Hampshire County Hospital, Russells Hall Hospital, St. Peter's Hospital, Torbay Hospital, York Hospital

These hospitals gave $>\mathbf{8 0} \%$ of their colorectal patients preoperative carbohydrate loading: Bedford Hospital, Churchill Hospital, Colchester General, Countess of Chester, Great Western, King's Mill, North Manchester General Hospital, Queen Elizabeth University Hospital Gateshead, Royal Blackburn, Royal Cornwall, Royal Devon and Exeter, Royal Hampshire County Hospital, Royal Lancaster Infirmary, Russells Hall, St Thomas' Hospital, St. Peter's Hospital, Stoke Mandeville Hospital, Torbay Hospital, Yeovil District Hospital, York Hospital

In thoracic surgery, only Bristol Royal Infirmary gave $>80 \%$ of their patients preoperative carbohydrate loading, and in burns and plastics, only Queen Victoria Hospital reached this goal.

No hospitals reached provided preoperative carbohydrate loading to at least $80 \%$ of their orthopaedic, head and neck, upper Gl or urology patients.

\section{Drinking within 24h of surgery: National Target $90 \%$}

$>90 \%$ of PQIP patients in these hospitals were drinking within $24 \mathrm{~h}$ of surgery: Aintree University Hospital, Basildon University Hospital, Bedford Hospital, Birmingham Heartlands, Bristol Royal Infirmary, Castle Hill, Chelsea and Westminster, Colchester General, Countess of Chester, Cumberland Infirmary, Darent Valley Hospital, Hereford County Hospital, King's Mill Hospital, Lister Hospital, Manchester Royal Infirmary, Musgrove Park Hospital, National Hospital for Neurology and Neurosurgery, Nevill Hall Hospital, Norfolk and Norwich University Hospital, Northampton General Hospital, Nottingham City Hospital, Papworth Hospital, Princess of Wales Hospital, Queen's Hospital, Burton upon Trent, Queen Elizabeth Hospital Birmingham, Queen Elizabeth University Hospital, Gateshead, Royal Berkshire Hospital, Royal Blackburn Hospital, Royal Bolton Hospital, Royal Cornwall Hospital, Royal Derby Hospital, Royal Lancaster Infirmary, Royal London Hospital, Royal National Orthopaedic Hospital, Royal Surrey County Hospital, Russells Hall Hospital, Sandwell General Hospital, Southmead Hospital, St George's Hospital, St. Peter's Hospital, Stoke Mandeville Hospital, Sunderland Royal Hospital, Tameside General Hospital, The James Cook University Hospital, The Royal Orthopaedic Hospital, Torbay Hospital, University Hospital Wales, University Hospital, Coventry, Warwick Hospital, Yeovil District Hospital, York Hospital

By specialty - these are the hospitals where patients were drinking within 24h of surgery:

Colorectal surgery: Bedford Hospital, Birmingham Heartlands Hospital, Broomfield Hospital, Churchill Hospital, Colchester General Hospital, Countess of Chester Hospital, Cumberland Infirmary, Hereford County Hospital, King's Mill Hospital, Nevill Hall Hospital, Norfolk and Norwich University Hospital, North Manchester General Hospital, Northampton General Hospital, Nottingham City Hospital, Princess of Wales Hospital, Queen's Hospital, Burton upon Trent, Queen Elizabeth University Hospital, Gateshead, Royal Berkshire Hospital, Royal Blackburn Hospital, Royal Bolton Hospital, Royal Cornwall Hospital, Royal Devon and Exeter Hospital, Royal Lancaster Infirmary, Russells Hall Hospital, Salford Royal Hospital, Sandwell General Hospital, Southmead Hospital, St George's Hospital, St Thomas' Hospital, St. Peter's Hospital, Stoke Mandeville Hospital, Tameside General Hospital, The James Cook University Hospital, Torbay Hospital, University Hospital, Coventry, Warwick Hospital, Watford General Hospital, Yeovil District Hospital, York Hospital

Urology: Birmingham Heartlands Hospital, Norfolk and Norwich University Hospital, Royal Devon and Exeter Hospital, Salford Royal Hospital, St George's Hospital, Sunderland Royal Hospital, The James Cook University Hospital, The Royal Marsden Hospital, University College Hospital, University Hospital, Coventry

Upper GI: None

Thoracics: Basildon University Hospital, Birmingham Heartlands Hospital, Bristol Royal Infirmary, Norfolk and Norwich University Hospital, Papworth 
Hospital, St George's Hospital, Wythenshawe Hospital

Orthopaedics: Royal National Orthopaedic Hospital, The Royal Orthopaedic Hospital

Spinal: National Hospital for Neurology and Neurosurgery, Royal National Orthopaedic Hospital

Burns and plastics: Queen Victoria Hospital

\section{Eating within $24 \mathrm{~h}$ of surgery: National target $80 \%$}

$>80 \%$ of patients were eating within $24 \mathrm{~h}$ of surgery in these hospitals: Aintree University Hospital, Basildon University Hospital, Bedford Hospital, Birmingham Heartlands Hospital, Bristol Royal Infirmary, Castle Hill Hospital, Charing Cross Hospital, Countess of Chester Hospital, Cumberland Infirmary, Hereford County Hospital, Lister Hospital, Musgrove Park Hospital, National Hospital for Neurology and Neurosurgery, Nevill Hall Hospital, Nottingham City Hospital, Papworth Hospital, Queen's Hospital, Burton upon Trent, Queen Elizabeth University Hospital, Gateshead, Royal Cornwall Hospital, Royal Derby Hospital, Royal National Orthopaedic Hospital, Royal Surrey County Hospital, Sandwell General Hospital, Southmead Hospital, St George's Hospital, Stoke Mandeville Hospital, Sunderland Royal Hospital, The Royal Orthopaedic Hospital, Torbay Hospital, University Hospital Wales, Wythenshawe Hospital

By specialty, $>80 \%$ of patients in these hospitals were eating within 24h of surgery:

Colorectal: Bedford Hospital, Broomfield Hospital, Castle Hill Hospital, Countess of Chester Hospital, Hereford County Hospital, North Manchester General Hospital, Nottingham City Hospital, Queen's Hospital, Burton upon Trent, Queen Elizabeth University Hospital, Gateshead, Royal Cornwall Hospital, Sandwell General Hospital, Southmead Hospital, Stoke Mandeville Hospital, Torbay Hospital, Watford General Hospital, Wythenshawe Hospital

Urology: Birmingham Heartlands Hospital, Salford Royal Hospital, St George's Hospital, Sunderland Royal Hospital, University Hospital, Coventry

Thoracics: Basildon University Hospital, Birmingham Heartlands Hospital, Bristol Royal Infirmary, Norfolk and Norwich University Hospital, Papworth Hospital, St George's Hospital, Wythenshawe Hospital

Orthopaedics: Royal National Orthopaedic Hospital, The Royal Orthopaedic Hospital

Spinal: National Hospital for Neurology and Neurosurgery, Royal National Orthopaedic Hospital

Burns and plastics: Queen Victoria Hospital

\section{Mobilising within $24 \mathrm{~h}$ of surgery: National target $85 \%$}

$>85 \%$ of patients were mobilising within $24 \mathrm{~h}$ of surgery in these hospitals: Aintree University Hospital, Basildon University Hospital, Bedford Hospital, Birmingham Heartlands Hospital, Bristol Royal Infirmary, Colchester General Hospital, Cumberland Infirmary, Gloucestershire Royal Hospital, Hereford County Hospital, Manchester Royal Infirmary, Musgrove Park Hospital, Norfolk and Norwich University Hospital, Papworth Hospital, Queen's Hospital, Burton upon Trent, Queen Elizabeth University Hospital, Gateshead,
Queen Victoria Hospital, Royal Hampshire County Hospital, Royal Lancaster Infirmary, Royal Surrey County Hospital, Russells Hall Hospital, Sandwell General Hospital, St George's Hospital, Stoke Mandeville Hospital, Sunderland Royal Hospital, University Hospital Wales, Warwick Hospital, Wythenshawe Hospital, Yeovil District Hospital, York Hospital

By specialty, $>85 \%$ of patients in these hospitals were mobilising within 24 h of surgery:

Colorectal: Bedford Hospital, Churchill Hospital, Colchester General Hospital, Cumberland Infirmary, Hereford County Hospital, Norfolk and Norwich University Hospital, Nottingham City Hospital, Queen's Hospital, Burton upon Trent, Queen Elizabeth University Hospital, Gateshead, Royal Hampshire County Hospital, Royal Lancaster Infirmary, Russells Hall Hospital, Sandwell General Hospital, Southmead Hospital, Stoke Mandeville Hospital, Warwick Hospital, Wythenshawe Hospital, Yeovil District Hospital

Urology: Birmingham Heartlands Hospital, Salford Royal Hospital, St George's Hospital, Sunderland Royal Hospital, The Royal Marsden Hospital, University College Hospital, University Hospital, Coventry

Upper GI: St Thomas' Hospital

Thoracics: Basildon University Hospital, Birmingham Heartlands Hospital, Bristol Royal Infirmary, Norfolk and Norwich University Hospital, Papworth Hospital, St George's Hospital, Wythenshawe Hospital

Orthopaedics: None

Burns and plastics: Queen Victoria Hospital

Head and Neck: None

DrEaMing within 24h of surgery: National target $80 \%$ $>80 \%$ of patients were DrEaMing within $24 \mathrm{~h}$ of surgery in these hospitals: Aintree University Hospital, Basildon University Hospital, Bedford Hospital, Birmingham Heartlands Hospital, Bristol Royal Infirmary, Hereford County Hospital, Musgrove Park Hospital, Papworth Hospital, Queen Elizabeth University Hospital, Gateshead, Royal Surrey County Hospital, Sandwell General Hospital, Stoke Mandeville Hospital, Sunderland Royal Hospital, University Hospital Wales

By specialty, > $85 \%$ of patients in these hospitals were DrEaMing within 24h of surgery

Colorectal: Bedford Hospital, Hereford County Hospital, Nottingham City Hospital, Queen Elizabeth University Hospital, Gateshead, Sandwell General Hospital, Stoke Mandeville Hospital

Urology: St George's Hospital, Sunderland Royal Hospital, University Hospital, Coventry

Upper GI: None

Thoracics: Basildon University Hospital, Birmingham Heartlands Hospital, Bristol Royal Infirmary, Norfolk and Norwich University Hospital, Papworth Hospital, St George's Hospital, Wythenshawe Hospital

Orthopaedics: None

Burns and plastics: Queen Victoria Hospital

Head and Neck: None 


\section{Collaborators}

A huge thank you and well done to all of our valued collaborators across the UK, whose hard work makes both PQIP and this report possible. This list is based on the names submitted to us by participating sites prior to report publication.

\begin{tabular}{|c|c|c|c|c|c|c|}
\hline Mayavan Abayalingam & Rachel Baumber & Rachel Burnish & Patricia Correia da Costa & Mandy Edwards & Lisa Grimmer & Jo Hubert \\
\hline Sue Abdy & Hannah Beadle & Karen Burns & Edward Costar & Mark Edwards & Chris Grocock & Danielle Huckle \\
\hline Laura Abernathy & Chloe Beard & Wendy Byrne & James Coulston & Ramesh Ekambaram & Mike Grocott & Karen Hudson \\
\hline Nkemjika Abiakam & Paul Bedford & Hazel Cahill & Nicholas Courtenay-Evans & Ashley Elden & Jessica Gunn & Alistair Hughes \\
\hline Andrea Ackerman & Kate Beesley & David Cain & Edward Courtney & Kerry Elliott & Paul Gunning & Tim Hughes \\
\hline lan Adams & Rose Beesley & Bridget Campbell & Amanda Cowton & Kaytie Ellis & Zoe Guy & Rachel Hughes \\
\hline Oluronke Adanini & Xiao Bei Zhao & Marta Campbell & Nicholas Crabtree & Ahmed El-Sharkawy & Laura Gwathil & Jenny Hughes \\
\hline Maame Aduse-Poku & Jan Belcher & Debbie Campbell & James Craig & Mark Eltringham & John Gwatkin & Rob Hull \\
\hline Neil Agnew & Martha Belete & Debra Campion & Jayne Craig & Jonathan Epstein & Denise Hadfield & Spencer Humphrys \\
\hline Michael Agyemang & Sarah Bell & Sara Campos & Andrew Cresswell & lony Evans & Brigid Hairsine & Adam Hunt \\
\hline Salman Ahmad & Jocelyn Bell & Joel Cardoso-Pereira & Nikki Crisp & Paul Evans & Bence Hajdu & Louise Hunt \\
\hline Sarfraz Ahmad & Gillian Bell & Suzanne Carey Jones & Jennifer Crooks & Matt Everson & Chandima Halahakoon & Lisa Hurley \\
\hline Anjum Ahmed-Nusrath & Jane Bellamy & Millie Carnachan & Jason Cross & Mark Fairbrass & Dawn Hales & Nik Husain \\
\hline Doug Aitken & Melissa Benavente & Sue Carnell & Carina Cruz & Joanne Falconer & Angela Hall & Melanie Hutchings \\
\hline Lindianne Aitken & Julia Benham-Hermetz & Ben Carrick & Peter Csabi & Sarah Farnell-Ward & George Hallward & Mark Ibrahim \\
\hline Louise Akeroyd & Zoe Bennettan & David Carter & Fiona Culley & Naila Farooq-lqbal & Geraldine Hambrook & Ugo thedioha \\
\hline Mansoor Akhtar & Jenny Bennett-Britton & Jaime Carungcong & Claire Dalton & Helen Farrah & Vincent Hamlyn & fer Illingworth \\
\hline Timothy Alce & Mariana Bernardo & Clarissa Carvalho & Zoe Daly & Catherine Farrow & Kate Hammerton & Arjuna Imbuldeniya \\
\hline Nick Aldridge & Stephanie Berry & Paula Carvelli & Sarah Daniels & Imogen Fecher & Sarah Hammond & Fiona Ingoldby \\
\hline Rod Alexander & Emily Bevan & Kim Chan & Diane Daniels & Teresa Ferreira & Fiona Hammonds & Francious loffidis \\
\hline Tamara Alexander & Anna Bewlay & Ben Chandler & Thelma Darian & Helder Filipe & Aimee Hampton & Matthew Jackson \\
\hline Hind Al-Husain & Chetan Bhan & Mogera Chandra & Bobby Dasari & Stuart Finn & Janice Hanley & Reni Jacob \\
\hline Syed Ali & Kailash Bhatia & Tristan Chapman & Dave Smith & Gracie Fisk & Vivienne Hannon & Jacqueline Routledge \\
\hline Jason Ali & Ravi Bhatia & Asif Chaudry & Beena David & Jill Fitchett & Daniel Hanratty & Vipul Jain \\
\hline Bilal Alkhaffaf & Arnab Bhowmick & Irfan Chaudry & Louisa Davies & Fiona Fitzgerald & Will Hare & Zara Jalal \\
\hline Charlotte Allan & Edward Bick & Katy-Jane Chick & Amanda Davies & Katie Flower & Daniel Harper & Rose Jama \\
\hline Clare Allcock & Janine Birch & Belinda Chieng & Charlie Davies & Jayne Foot & Andrea Harren & Sunil Jamadarkhana \\
\hline Wei-Lin Allen & Sian Birch & Anna Chillingworth & Richard Davies & Selina Ford & Yasmin Harrington- & Katherine James \\
\hline Jo Allison & Janine Bird & Mahindra Chincholkar & Roger Davies & Jessica Forrester & Davies & Parandeep Jandu \\
\hline Denise Almond & Brian Bisase & Gayathri Chinnappa Srinivas & Samantha Davies & Greg Forshaw & Stephen Harris & Anna Janowicz \\
\hline Ziad Alrifai & Ethel Black & Sadasivan Chinniah & Jenny Davis & Damon Foster & John Harris & Anne Jayne Brien \\
\hline Elana Anastasescu & Lauren Blackburn & Sara Churchill & Khaled Dawas & Ming Fung & Clair Harris & Richard Jennings \\
\hline Edward Andrade & Verity Blackburn & Ciaponi & Andrew Day & Jackie Furlong & Colin Harris & Emily Jeynes \\
\hline Prematie Andreou & Doug Blackwood & Emma Clarey & Toni de Freitas & Rosie Furness & Sanjay Harrison & Shaman Jhanji \\
\hline Eleanor Andrews & Jackie Bladon & Amy Clark & Joanne Deery & Kito Fusai & Alister Hart & Mhairi Jhugursing \\
\hline Gillian Ansell & Kevin Blizzard & Thomas Clark & Peter Delve & Claire Gabriel & Emma Hartland & nnett \\
\hline George Antoniou & Melanie Bloor & Richard Clark & Amit Deshmukh & e Gallagher & Robert Hartley & Teishel Joefield \\
\hline Gill Arbane & Aneta Bociek & Sheron Clarke & Somi Desikan & Joanne Galliford & David Harvie & Summayyah Jogi \\
\hline Giuseppe Aresu & Andrea Boedo & Sarah Clarke & Anne Devine & Carina Galpin & Liz Hawes & Helgi Johannsson \\
\hline Michael Argent & Clare Bolger & Hannah Clarke & Jugdeep Dhesi & Fang Gao Smith & Nancy Hawkins & Rebekah Johnson \\
\hline Susanne Armitage & Pieter Bothma & Tristan Clarke & Priya Dias & Amina Garcia & Christine Hawkins & Linda Johnson \\
\hline Glenn Arnold & Anne-Marie Bougeard & Peter Coe & Chimverly Diaz & Mark Garfield & Kat Haynes & Joanne Johnson \\
\hline Jon Arnot-Smith & Rebecca Boulton & Leon Cohen & Matt Dickinson & Zoe Garland & Olivia Hayward & Rob Johnston \\
\hline Linda Ashley-Edden & Jessica Bowen & Libby Cole & Lisa Ditchfield & Theresa Garratt & Jess Heaps & Carolyn Johnston \\
\hline Nadeem Ashraf & Sophie Boyd & Martin Cole & Hiren Divecha & James Garrod & Chantelle Heppolette & Dawn Johnstone \\
\hline Anam Asif & Sharon Boyne & Andrea Cole & Toby Dixson & Philip Gedling & Sarah Herbert & Rhidian Jones \\
\hline Sheila Avery & Andrew Bracewell & Helen Cole & Emma Dougherty & Emma Gendall & Emily Hetherington & Cathy Jones \\
\hline Omer Aziz & Julie Bracken & Alison Colhoun & Annette Dowdell & Roman Genetu & Sarah Hierons & Claudette Jones \\
\hline Ewa Babisz & Joanne Bradley-Potts & Peter Collett & Claire Dowse & Emma Gent & Susan Hill & Lyndon Jones \\
\hline Morgan Back & John Bramall & Julie Colley & Steve Drage & Simon George & Matt Hill & Colette Jones-Criddle \\
\hline Sheeba Badu & Debbie Branney & Dawn Collier & Dragos Dragnea & Norma Gibbons & Simon Hindley & Lesley Jordan \\
\hline Craig Bailey & Elizabeth Brannigan & Nikki Collings & Kate Driver & Ranjit Gidda & d Hobbs & Matt Julian \\
\hline Tessa Bailey & Philip Braude & Rachel Collis & Ronald Druyeh & Kayleigh Gilbert & Elizabeth Hodge & Miriam Kadry \\
\hline Pearl Baker & Barbara Bray & Thomas Collyer & Leon Dryden & Julian Giles & Tim Hodgkins & Prashant Kakodkar \\
\hline Madhu Balasubramaniam & David Brealey & Edward Combes & Stephen Duberley & Marc Gimenez & Tracey Hodgkiss & Vidya Kasipandian \\
\hline Mansoor Bangash & Andrew Brennan & Clare Conlon & Lucy Dudgeon & Kim Giraud & Gemma Hodgson & Ramanathan \\
\hline Samantha Banks & Matthew Bridge & Louise Conner & Sarah Duff & Jon Glass & James Holding & Kasivisvanathan \\
\hline Smita Bapat & Anne-Jayne Brien & Karen Connolly & Stephanie Dukes & Yvonne Gleeson & Maureen Holland & Tasneem Katawala \\
\hline Chris Barben & Elaine Brinkworth & Daniel Conway & Steven Dunkley & Kelly Goffin & Ann Holmes & Jasmin Kaur \\
\hline Musa Barkeji & Catherine Britton Jones & Tim Cook & Almu Duran-Rosa & Dhanny Gomez & Cassandra Honeywell & Sharon Kaur \\
\hline Rebecca Barker & Kathryn Brodbelt & Sarah Cooper & Rebecca Dyar & Prisca Gondo & Liz Hood & Ambreen Kauser \\
\hline Debi Barnes & Fiona Brogan & Nadine Cooper & Simon Dyer & Romana Govindaraju & Kathleen Horan & Anne Keen \\
\hline Veronica Barnes & Helen Bromhead & Lisa Cooper & Rebecca Dyer & Lia Grainger & Anil Hormis & Natalie Keenan \\
\hline Gillian Barnett & Adam Brooks & Karen Copeland & James Eales & Gayna Grantham & Deborah Horner & Jessica Kelly \\
\hline Nina Barratt & Johanna Brown & Zoe Copp & Megan Eardly & Juan Graterol & Tanvir Hossain & Andrea Kelly \\
\hline Lisa Barrell & Michelle Bruce & Jim Corcoran & Jonathan Easterbrook & Neus Grau Novellas & Kate Howard & Peter Keltie \\
\hline James Barrowman & Zoe Brummell & James Corcoran & Christine Eastgate & Irina Grecu & Linda Howard & Clive Kelty \\
\hline Andy Bates & Sarah Buckley & Henry corner & Tracy Edmunds & Louise Greig & Georgina Howell & Christopher Kennedy \\
\hline Katherine Batte & Rhian Bull & Darryl Cornish & Emma Edmunds & Caris Grimes & Lucie Howie & Jo Keogh \\
\hline
\end{tabular}




\begin{tabular}{|c|c|c|c|c|c|c|}
\hline $\begin{array}{l}\text { Amy Kerr } \\
\text { loyce Kibaru }\end{array}$ & Sola Makinde & Susan Moss & Judith Partridge & Andrew Renehan & John Skinner & $\begin{array}{l}\text { Madeleine Thyssen } \\
\text { Helen T-Michael }\end{array}$ \\
\hline $\begin{array}{l}\text { Joyce Kibaru } \\
\text { Katie King }\end{array}$ & & $\begin{array}{l}\text { Bhvani Mothe } \\
\text { Lorraine Motvel }\end{array}$ & $\begin{array}{l}\text { Jonathan Pass } \\
\text { laimin Patel }\end{array}$ & $\begin{array}{l}\text { Johannes Retief } \\
\text { Adam Revill }\end{array}$ & $\begin{array}{l}\text { Amy Slack } \\
\text { Kirstie Smith }\end{array}$ & $\begin{array}{l}\text { Helen T-Michael } \\
\text { Gabriella Tomkova }\end{array}$ \\
\hline $\begin{array}{l}\text { Katie King } \\
\text { Maureen King }\end{array}$ & $\begin{array}{l}\text { Mira Manoharan } \\
\text { Hosnieh Marbini }\end{array}$ & $\begin{array}{l}\text { Lorraine Motuel } \\
\text { Jessica Muchmore }\end{array}$ & $\begin{array}{l}\text { Jaimin Patel } \\
\text { Rajan Patel }\end{array}$ & Nicolas Rey de Castro & $\begin{array}{l}\text { Rirstie Smifh } \\
\text { Tim Smith }\end{array}$ & Zara Townley \\
\hline Jane Kingham & Kalimuthu Marimuthu & Karim Muhammad & Johanna Paterson & Anna Reyes & Chris Smith & Dawn Trodd \\
\hline Harry Knight & Nicky Marks & Hassan Mukhtar & Kate Paterson & Ramasamy Rhadika & Darren Smith & Maria Troy \\
\hline John Knight & Suzie Marriott & Amanda Mulholland & Abigail Patrick & Matthew Rhodes & Austen Smith & Julia Tubbs \\
\hline Peter Knowlden & Emma Marshall & Joe Mullender & Mathew Patteril & Karen Rhodes & Dave Smith & Olga Tucker \\
\hline Shum Koin Lon & Jane Martin & Amanda Mullholland & Dan Paul & Anna Riccoboni & Julian Smith & James Tulloch \\
\hline Dimitrios & Tim Martin & Maxene Murdoch & Mark Paul & Zoe Ridgway & Jason Smith & Victoria Turner \\
\hline Konstantopoulos & Sarah Martindale & Henry Murdoch & Varghese Paul & Stephanie Ridgway & Rachel Smith & Ian Turner-Bone \\
\hline Christos Kontovonisious & Guillermo Martinez & Rosie Murdoch & Mark Pauling & Corinne Rimmer & Neil Smith & Cadice Tyers \\
\hline Damir Kosutic & Laura Martins & Jo Murfin & Stephanie Pauling & Jenny Ritzema & Theresa Smith & David Tyl \\
\hline Kartik Kota & Gladys Martir & Anthony Murphy & Nikhil Pawa & Vanessa Rivers & Jennifer Smith & Stephen Usher \\
\hline Bobby Krishnachetty & Sushil Maslekar & Zoe Murphy & Corinne Pawley & Stephen Roberts & Fran Smith & Chandrashekhar \\
\hline Priya Krishnan & Clare Mason & Katherine Murray & Louise Pearson & Martyn Robertson & Debbie Smyth & Vaidyanath \\
\hline Monika Krupa & Alexandra Matson & Dave Murray & Andrew Peethamsingh & Nikola Robinson & Rebecca Snell & Chandra Vaidyanath \\
\hline Agniezsa Kubisz-Pudelko & Rosanna Maurin & Rosemary Musanhu & Suzannah Pegler & Lisa Roche & Manisha Sodhi & Luke Vamplew \\
\hline Mohan Kumar & Debbie Mawson & Esther Mwaura & Melchizedek & Kirsty Rogers & Kathryn Sollesta & Emma Varley \\
\hline Vikas Kumar & John May & Priya Nadarajah & Penacerrada & Melissa Rosbergen & Julian Sonksen & Nikhil Vasdev \\
\hline Snehal Kumbhare & Denzil May & Seema Nadkarni & Lisa Penny & Alastair Rose & Simon Sparkes & Rajiv Vashisht \\
\hline Rajeev Kushwaha & Frank McAuley & Zin Naing & Stacey Pepper & Joanne Rothwell & William Speake & Frances Venn \\
\hline Inese Kutovaja & Laura McCafferty & Rajesh Nair & Lauren Perkins & Jacqueline Routledge & Will Spencer & Joanne Vere \\
\hline Thyra Kyere-Diabour & Ananya McCarthy & Ashok Nair & Raj Pervalli & Geena Roy & Yolande Squire & Mark Vertue \\
\hline James Lai & Jacqueline Mccormick & Priya Nair & Cecilia Peters & James Royal & Gemma Squires & Julie Vickery \\
\hline Sandeep Lakhani & Bruce McCormick & Shireen Naqui & Chris Peters & Anna Roynon Reed & Philippa Squires & Dale Vimalachandran \\
\hline Aroon Lal & Richard McCormick & Andres Naranjo & Carroll Petty & Webster Rushesha & Seema Srivastava & Marcela Vizcaychipi \\
\hline Jo Lambert & David McCrettton & Nagendra Natarajan & Alexander Philips & Lucy Ryan & Frank Stafford & Ravinder Vohra \\
\hline Ben Lane & Evanna McEvoy & Noel Nathaniel & Andrew Pick & Christine Ryan & Claire Stapleton & Lewis Waggett \\
\hline Tamsin Lane & John McGrath & Shakira Nathoo & Mikolaj Pielas & Parv Sains & Lorraine Stephenson & Mai Wakatsuki \\
\hline Katy Later & Sophie McGrath & Deanna Naylor & Manuel Pinto & Amina Sajid & Joseph Stevens & Jessica Walding \\
\hline Maurice Lau & India McKenley & Aaron $\mathrm{Ng}$ & Lucy Pippard & Mark Salmon & Nathalie Stevenson & Susanna Walker \\
\hline Helen Lawrence & Emma Mckenna & Yang $\mathrm{Ng}$ & Bala Piramanayagam & Collette Samuels & Richard Stewart & Elaine Walker \\
\hline Tessa Lawrence & Elizabeth McKerrow & Onie Ngwenya & James Plumb & Amanda Sanderson & Duncan Stewart & James Walkington \\
\hline Heidi Lawson & Euan McLaughlin & Sotiris Nicholas & Kathryn Pointon & Siva Sangaralingham & Adrienne Stewart & Deirdre Wallace \\
\hline William Lawson-Brown & Laura Mcleavy & Claire Nicholas & Sara Polhill & Sumayer Sanghera & Julian Stone & Jo Waller \\
\hline Tom Lawton & Fiona McNeela & Tom Nightingale & Michael Pollard & Seliat Sanusi & Mark Stoneham & Lucy Walsh \\
\hline Susannah Leaver & Margaret McNeil & Louise Nimako & Fiona Pomeroy & Laura Sarmiento Valero & Sharon Storton & Michelle Walter \\
\hline Julie Lebas & Denise McSorland & Marie Nixon & Jim Poncia & Christine Sathananthan & Alexa Strachan & Daniel Wang \\
\hline Gemma Lee & Johannes Mellinghoff & Hannah Noble & Mel Poole & Nicholas Savage & Richard Struthers & Sinead Ward \\
\hline Michelle Leemans & Teresa Melody & Harriet Noble & Claire Potter & Heather Savill & Charlotte Strzelecki & John Ward \\
\hline Mairi Leggatt & Julie Melville & Aidan Noon & Alison Potter & Amrinder Sayan & Daren Subar & Sally Ward-Booth \\
\hline Cynthia Leigh & Arun Menon & Julie North & Gail Pottinger & Magda Sbai & Akshay Sule & Gregory Warren \\
\hline Dee Leonard & Stuart Mercer & Kribashnie Nundlall & Sarah Powell & Andrea Scala & Mark Sullivan & Tim Warrener \\
\hline David Leslie & Pauline Mercer & Ruth O'Dowd & Chris Powell-Wiffen & Mark Scarfe & Jaysimha Susarla & Richard Wassall \\
\hline Denny Levett & Megan Meredith & Paul O'Loughlin & Oliver Pratt & Rosaria Scarpinata & Paul Sutton & Lucy Waterfield \\
\hline Christopher Levett & Susan Merotra & Vikki O'Loughlin & Joel Prescott & Lyndsay Scarratt & Asheesh Suxena & Grant Watling \\
\hline David Levy & Rachel Meskell & Jonathan Ockrim & Karen Prevc & Anne Scase & Andrew Swain & Jane Watson \\
\hline Juliette Li Wan Po & Clare Mewies & Tessa O'Halloran & Anna Price & Louise Schonborn & Catherine Swann & Nicholas Watson \\
\hline Rosario Lim & Maria Milburn & Maxine Okello & Carly Price & Simon Scott & Kathy Swanson & Dave Watson \\
\hline Woei Lin Yap & Martin Millar & Alison O’Kelly & Stephanie Prince & Michaela Scott & Mike Swart & Philip Waugh \\
\hline Jonathan Lloyd Evans & Jessica Miller & Padraig O'Scannill & Florence Prior & Chloe Searles & Katie Sweet & Emily Weaver \\
\hline Alison Loftus & Don Milliken & Ayo Oshowo & Ffion Pritchard & Karthikeyan Selvaraju & Yadullah Syed & Jonathan Williamson \\
\hline Ruth Longfellow & Simran Minhas & Harriet Owen & Mark Pulletz & Neel Sengupta & Abdul Syed & Matthew Whitehead \\
\hline Rita Lopes & Gary Minto & Sara Owen & Anne Pullyblank & Victoria Senior & Rebecca Symes & Danielle Wilcock \\
\hline Rui Lopes & Sarah Mitchard & Jamie Pack & Bally Purewal & Darreul Sewell & Gemma Szabo & Laura Wilding \\
\hline Bruno Lorenzi & George Mochloulis & Andrew Padwick & Charlotte Quamina & Helen Seymour & Kata Szabo & Emma Wiliams \\
\hline Gretel Loten & Jignasa Modha & Valerie Page & Ramasamy Radhika & Nirav Shah & Melanie Tan & Gail Williams \\
\hline Louise Hunt & Faizal Mohomed-Hossen & Katherine Pagett & Govindaraju Ramana & Samir Shah & James Taylor & Hannah Wilson \\
\hline Robert Loveridge & Helen Molloy & Anirudda Pai & Sean Ramcharan & Deep Shah & Frances Taylor & Jonathan Wilson \\
\hline Justine Lowe & Georgia Monantera & Glykeria Pakou & Lidia Ramos & Andy Shannon & Michelle Taylor & Danny Wong \\
\hline Clare Lummis & Rugaia Montaser & Carole Paley & Nirmalabaye Ramsamy & Sophie Shapter & Natalie Taylor & Andrew Woodgate \\
\hline Val Luoma & Jane Montgomery & Claire Palmer & Fiona Ramsden & Emma Sharkey & Emma Temlett & Jade Woolley \\
\hline Craig Lyness & Maria Moon & Janet Palmer & Simon Rang & Helen Sharples & Nila Tewari & Caroline Wrey Brown \\
\hline Marc Lyons & Claire Moore & Shivani Pandya & Mohan Ranganathan & Adnan Sheikh & Azeem Thahir & Retno Wulandari \\
\hline Sara Ma & Tim Moore & Kerry Paradowski & Valluvan Rangasamy & Tom Sheppard & SriKandan Thangavel & Babel Zaheer \\
\hline Neil MacDonald & Alison Moore & Dhruv Parekh & Sameer Ranjan & Julie Sheriff & Mini Thankachen & Ahmad Ziyad \\
\hline Mark MacGregor & lain Moppett & Zarah Paris & Rajashankar Rao & Paula Shirley & Bubby Thava & \\
\hline Ami Mackay & Lucy Moran & Linda Park & Steph Ratcliffe & Anthony Short & Abrie Theron & Our thanks also to \\
\hline Ailie Mackenzie & Tom Morgan-Jones & Jane Parker & Dave Raw & Charmaine Shovelton & Kumaran Thiruppathy & the other collaborators \\
\hline Jennifer MacLellan & Catherine Moriarty & David Parkinson & Shilpa Rawat & Pauline Sibley & Kannan Thogulava & not listed above who \\
\hline Joe Macmillan & Clare Morkane & Valerie Parkinson & Caroline Reavley & Constantinos Simillis & Caroline Thomas & work so hard at local \\
\hline George Madden & Rebecca Morris & Sanjay Parmar & Jon Redman & Helen Simmons & Sue Thomas & level to deliver PQIP. \\
\hline Karen Maher & Lucy Morris & Julia Parnell & Ellie Reeves & Joanna Simpson & Vicky Thomas & \\
\hline Parisa Mahjoob-Afag & Sophie Morris & James Parry & Hafiz Rehman & Janet Sinclair & Rebecca Thompson & \\
\hline Christopher Mahon & Andy Morrison & Penny Parson & Karen Reid & Jambulingam Sivasamy & Leah Thompson & \\
\hline Cathryn Mainwaring & Alison Moss & Georgie Parsons & Simon Reid & Subash Sivasubramaniam & Chris Thorn & \\
\hline
\end{tabular}




\section{PQIP Project Team}

Ramani Moonesinghe, Giuseppe Aresu, Sam Bampoe, Rachel Baumber, James Bedford, Matthew Bedford, Anne-Marie Bougeard, Alexandra Brent, Martin Cripps, Jenny Dorey, Sharon Drake, Helen Ellicott, David Gilhooly, James Goodwin, Aleksandra lgnacka, Sandy Jackson, Irene Leeman, Jose Lourtie, Peter Martin, Dorian Martinez, Dermot McGuckin, Arun Sahni, Katie Samuel, Cristel Santos, Pritam Singh, Mike Swart, Olga Tucker, Abigail Vallance, Cecilia Vindrola, Ravinder Vohra, Duncan Wagstaff, Samantha Warnakulasuriya, Karen Williams, Jonathan Wilson

PQIP is supported by the National Institute for Health Research's Clinical Research Network through portfolio adoption.

PQIP is funded by the Royal College of Anaesthetists, the Health Foundation, and the UCL/UCLH NIHR Surgical Outcomes Research Centre.

PQIP is delivered by the NIAA Health Services Research Centre and sponsored by University College London.

\section{NIAA Health Services Research Centre}

The Royal College of Anaesthetists

Churchill House

35 Red Lion Square

London WC1R 4SG

\section{2019 Royal College of Anaesthetists}

No part of this publication may be reproduced, stored in a retrieval system, or transmitted in any form or by any other means, electronic, mechanical, photocopying, recording, or otherwise, without prior permission, in writing, of the Royal College of Anaesthetists.

While the Royal College of Anaesthetists has endeavoured to ensure that this document is as current as possible at the time it was published, it can take no responsibility for matters arising from circumstances which may have changed, or information which may become available subsequently.

Published by the Royal College of Anaesthetists

Registered Charity No: 1013887 | Registered Charity in Scotland No: SCO37737 | VAT Registration No: GB 927236418

www.pqip.org.uk 